Portland State University

PDXScholar

1976

\title{
A qualitative assessment of Clark County's mental health delivery system
}

John L. Hutchison

Portland State University

Follow this and additional works at: https://pdxscholar.library.pdx.edu/open_access_etds

Part of the Social Policy Commons, Social Welfare Commons, and the Social Work Commons Let us know how access to this document benefits you.

\section{Recommended Citation}

Hutchison, John L., "A qualitative assessment of Clark County's mental health delivery system" (1976). Dissertations and Theses. Paper 1774.

https://doi.org/10.15760/etd.1772

This Thesis is brought to you for free and open access. It has been accepted for inclusion in Dissertations and Theses by an authorized administrator of PDXScholar. Please contact us if we can make this document more accessible: pdxscholar@pdx.edu. 


\title{
A Qualitative Assessment of Clark County's Mental Health Delivery System
}

\author{
by \\ John L. Hutchison \\ A practicum submitted in partial fulfillment of the \\ requirements for the degree of
}

MASTER OF

SOCIAL WORK

Portland State University

1976 


\section{ACKNOWLEDGMENTS}

Any research project results from the efforts of many people. I would like to take this opportunity to acknowledge and thank those who participated in this study: The Health and Welfare Planning Council who sponsored and published the original work; Dr. Patricia S. Anderson, Director of Research, Health and Welfare Planning Council, who not only provided me with wise council but had confidence in my ability to satisfactorily complete the study; Ms. Nancy Koroloff, Portland State University, School of Social Work faculty advisor, who provided ideas and encouragement out of which this study grew; Pat Olesen who put many hours into typing, offering suggestions, and listening; Charlotte Wellman and Jerry Burns for their careful and competent editing.

I am profoundly grateful also to Mr. Clifford Greenlick, my friend and colleague at the Health and Welfare Planning Council, for having put aside his own work in order to help me in editing and discussion of many substantial points and arguments raised in the study.

I have dedicated this study to Lew and to Henry Dobermann; their comfort and support during this study were of inestimable value, and contributed to its completion. 
TABLE OF CONTENTS

PAGE

ACKNOWLEDGMENTS .................. i

LIST OF TABLES ....................... ii CHAPTER

I INTRODUCTION......................

II OVERVIEW $\ldots \ldots \ldots \ldots \ldots \ldots \ldots \ldots \ldots \ldots \ldots \ldots$

III METHODOLOGY..................... II

IV RESULTS....................... 19

Measures of Effectiveness: Program

Assessment

Measures of Satisfaction: Consumer Assessment

Measures of Satisfaction: Detectors and Providers Assessment

$\mathrm{V}$ RECOMMENDATIONS................. 52

Program

Staffing

Physical Facilities

Relationship to the System

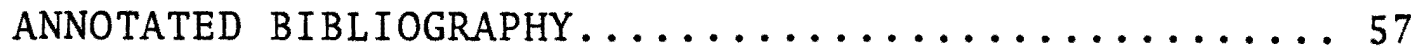

APPENDIX A: Agency Questionnaire........... 70

APPENDIX B: Detector and Provider Questionnaire... 84

APPENDIX C: Consumer Questionnaire........... 98 


\section{LIST OF TABLES}

PAGE

1. Responses to Staffing and Training and Specialization Questions...............21

2. Responses to Physical Facility and Program Questions....................25

3. Memories of Consumers Regarding Feelings at Time of Initial Visit to Mental Health and Family Services Center............... 32

4. Memories of Consumers Regarding Feelings at Time of this Survey................... 33

5. Mean Improvement of Active and Inactive at Time of Questionnaire................. 34

6. Perceptions of the Consumers regarding the Status of their Problems............... 35

7. Rating of Consumers Expectations Regarding Services Received....................36

8. Rating of Consumers Regarding Select Staff Characteristics................... 38

9. Consumers Responses Regarding Recommendation of Mental Health and Family Services Center... 39

10. Consumers Responses Concerning Seeking Help From Other Professionals or Agencies Prior or Since Visitation to Mental Health and Family Services Center................40

11. Consumers Responses Regarding Therapist Interaction......................4 41

12. Consumers Responses Concerning Usefulness of Mental Health and Family Services Center......4 4 


\section{LIST OF TABLES CONTINUED}

PAGE

13. Rating of Eleven Community Agencies by Detectors and Private Practice Providers...... 47

14. Ranking of Most Prevalent Reasons by Detectors for not Referring to Community Agencies...... 50 
CHAPTER I

\section{INTRODUCTION}

During the past several years, service delivery for mental health in Clark County has changed dramatically. The increase in funding from the federal government in the $1960^{\prime} \mathrm{s}$, the trend toward de-institutionalization, the emphasis on local control and administration, the proliferation of service agencies and types of programs, and the increase in demand for mental health services, has created the complex, multi-dimensional, multi-funded "system" called the mental health system.

This increased complexity in the service delivery system has resulted in confusion among decision makers, consumers, providers of service, and the community at large. This confusion has manifested itself in a call for accountability. For local agencies receiving federal funds, accountability has been primarily an audit function. With respect to private agencies receiving private donations, accountability has been limited to budget presentations and rudimentary data collection, i.e., numbers served, client/staff ratios, program utilization by clients and the like. In general, no systematic, continous effort has been made to develop a full range of program evaluation accessible to decision makers, consumers, providers of service, and the community at large. 
In addition to the influence on the mental health system due to the increasing demands for accountability, elected officials are often becoming administrators of mental health funds. This increase in the span of control of elected officials has created greater visibility for their positions, thus bringing pressure from consumers as well as the community at large, to the mental health system.

Recognizing the above trends in mental health care, the Clark County Commissioners contracted with the Health and Welfare Planning Council (HWPC) to investigate and provide information describing the nature of the mental health service delivery system in Clark County, and to report this information to the Commissioners and the community at large. In addition, the study attempts to evaluate the effectiveness of that system in the delivery of service.

The study research procedure used by the Health and Welfare Planning Council was to bring ad hoc citizen committees together to develop recommendations from data gathered by staff. Six committees were formed around the key questions that were identified by the Clark County Commissioners as requiring answers. They were as follows:

What should a mental health system be?----Conceptual Model Committee

Do we really need more service?----Needs Assessment Committee

Who pays for mental health care?----Finance Committee 
Are people getting lost in the system?-.--Continuity of Care Committee

How can we prevent mental ill health?----Prevention Committee

Is it doing any good?-----

Quality of Care Committee

Examination of the whole mental health delivery system is beyond the scope of this study. For this reason, the Quality of Care component will be the focus of this independent examination. In the examination of Quality of Care, it may be necessary to briefly describe the mental health delivery system and other aspects examined by the Health and Welfare Planning Council.

For purpose of exposition, the structure of the report is broken down into five functional areas: Overview, Methodology, Results, Recommendations and Annotated Bibliography. 
CHAPTER II

OVERVIEW

The lack of universally accepted definitions or standards for measurement and monitoring of the concept of quality in the mental health and illness field is derived from essentially three sources: 1) mental health and illness is not a simple, single-faceted phenomenon; 2) there are a diversity of programs, activities, and techniques which are directed toward helping people function optimally in a changing social environment; and 3 ) there are multiple demands placed on mental health clinics by expected outcomes or products. The upshot of this ambiguity in the mental health and illness field results in definitions and standards of quality particular to the individual or group which defines it. Thus, the quality of a mental health program can be viewed as a continuum of assessments of the services of that program, and may range from being absolutely destructive to the individual and counter-productive from a societal standpoint, to that which is deemed "successful" in every situation.

Historically, quality of care standards and definitions, when applied, have usually related to the number of patients, (in-put/out-put, so to speak), recidivism rates, client 
evaluation, public awareness and self-assessments. ${ }^{1}$ Generally, when these measures have been applied (with the exception of recidivism and in-put/out-put measures), they were subjective in nature. In recent years there has been an increased demand for objective program evaluation.

Drawing primarily from past and current measures, this paper will use the term "quality" as a synonym for a relatively high level of service, which includes: 1) evaluation of the agencies' programs, to include measuring the effects of the programs against the goals they set out to accomplish; and 2) attitudes and perceptions of agencies' programs by individuals and groups within the community.

High quality of care is not something that just happens to an agency's program; rather, it must be promoted, developed, protected and controlled. The community agency, and the service delivery system of which it is a part, must have built-in mechanisms for monitoring their operations in order to assure relatively objective decisions concerning budget allocations and program planning.

While "quality" may be determined in part by politics, theoretical orientations, tradition, funding sources, professional training standards (such as peer review, 1 iscensing and formal standards relation to structure, organization,

${ }^{1}$ Robert P. Gregovich, "What Kind of Measures to Use", paper presented at the Western Conference on the Uses of Mentai Health Data. Bolder, Colorado, October 1970, p. 19. 
operating policies, staffing, physical plant and equipment, conformity to such measures alone must not be taken as a measure of quality. Quality should be measured by the effects of a program against the goals it sets out to accomplish, while also assessing the worth of those goals. ${ }^{2}$ Therefore, in order to meet the standards for high-quality services, an agency must demonstrate that it has effective methods of program evaluation to measure the effects of the program in light of adopted goals. Further, they must determine that the evaluation is coordinated with built-in mechanisms for constant review and modification of agency operations.

Program evaluation, a primary means of measuring quality of care, is basically a judgement of worth, an appraisal of value. Evaluation is an effort to observe and assess the operations of a program, and is used to detect problems in progress, to examine and monitor the processes or mechanisms within the program, and to measure the effectiveness and efficiency of the methods used for the program. Evaluation is essentially a control device, one of the tools decisionmakers should and often do use, when looking at a program or a program component. Evaluation increases the rationality of policy-makers by providing them with information, regarding: 1) how well the program is meeting the purposes for which it was established; and 2) whether the program should be continued,

2Ibid., p. 19. 
expanded, cut back, modified or abandoned.

Margurite McIntire of the National Institute of Mental Health has some interesting insights about evaluation. She feels that to be useful, evaluation efforts require substantive investment of staff and financial resources in addition to the backing of management. As a general rule, $5 \%$ to $10 \%$ of all staff time has been identified as necessary for successful evaluation. ${ }^{3}$ However, historically the national average of only $2.7 \%$ of staff time has been devoted to research and evaluation .

It is evident that the process of evaluation is highly complex and subjective. It inherently involves a combination of basic assumptions underlying the program being evaluated and those who are doing the evaluation. ${ }^{4}$ In order to reduce this intrinsic subjectivity, evaluation should adhere as closely as possible to the principles and procedures of the scientific method. 5

${ }^{3}$ Margurite McIntire, et al, Componants of Program Evaluation Capability in Community Mental Health Centers (San Francisco: Langley Porter Neuropsychiatric Institute, 1972 p. 6

${ }^{4}$ Edward Suchman, Evaluative Research, (New York: Russell Sage Foundation, 1976) p. 27-40

5 Ibid., p. $27-40$ 
In general, the scientific method addresses such issues as appropriate data-gathering techniques, proper types of experimental designs, survey methods, sampling techniques, statistical analysis, etc. Although such issues are important in controlling subjectivity, they should not be the primary consideration in dictating the types of measures that are used in any particular evaluation.

Dr. Robert P. Gregovich, a leader in evaluation research, points out that the implementation of program evaluation will be delayed if "proper" methodology is emphasized as the primary consideration. 6 With an understanding of the dimension of researching the ideal (strict adherance to the canons of scientific inquiry), three measures relevant to program evaluation were selected. They are: Measures of efficiency, measures of effectiveness, and measures of satisfaction. 7

\section{Measures of Efficiency}

Measures of efficiency refer to the utilization of resources and time, translated into money and usually referred to as cost benefit analysis. Activities related to this category include statistical descriptions of clients, accounting for expenditures of funds and staff effort, patient/ staff ratios, program utilization by clients, and analysis of

\footnotetext{
${ }^{6}$ Gregovich, What Kind of Measures to Use, p. 12 . 7 Ibid. , p. 18.
} 
location and space.

\section{Measures of Effectiveness}

Measures of effectiveness refer to what are usually considered to be measures of success, performance measures, or treatment outcome indicators. Examples include the number of patients cured or rehabilitated, and the recidivism rate. This information may be derived from case records, court records, staff assessments, outside assessments, and peer review. In order to measure effectiveness a clear statement of agencies goals is required; answering questions of: How much was accomplished relative to the goal; did any change occur; was the change the one intended?

\section{Measures of Satisfaction}

Measures of satisfaction refer to the opinions, statements and actions of persons whose judgements may influence the way in which a program is designed, implemented, or continued. Examples include attitude surveys, questionnaires that assess patient satisfaction with treatment or service, and perceptions made by community detectors and practitioners, i.e., clergymen, school counselors and principals, physicians, and private counselors, psychiatrists and psychologists.

Of these measures, only the measures of effectiveness and satisfaction deal directly with quality. Measures of efficiency deal only peripherally with quality, and primarily 
serve a managerial function. However, although measures of effectivenss and satisfaction deal directly with quality, agencies must first deal with measures of efficiency before the measures of effectiveness and satisfaction can be met. For example, if one wishes to determine the success in achieving a particular goal in a given program (measure of effectiveness), information must be available regarding the number of patients in the program (measure of efficiency). 
CHAPTER III

\section{METHODOLOGY}

The researcher was immediately faced with a limited amount of time in designing and completing the Quality of Care component of the Mental Health Study. Accordingly, the methodology was structured to gather the largest amount of information in a relatively limited amount of time.

As a first step, a literature review was conducted resulting in the creation of some basic concepts relative to the topic of study. ${ }^{8}$ After initial familiarization with the literature and discussion of several substantial points and arguments contained therein, determination was made with respect to what type of measures would be used, and who would be asked to participate.

From these initial discussions and literature review, it was determined that quality would be examined in the aggregate sense with respect to the measures of effectiveness and satisfaction. All community agencies that provided counseling and/or mental health services would be assessed relative to various measures of effectiveness. Detectors, that is,

${ }^{8}$ For a more detailed description of material used in the study, see annotated bibliography. 
clergymen, physicians, school counselors and principals, and private practitioners such as counselors, psychiatrists and psychologists as well as consumers of Mental Health and Family Services Center would be surveyed relative to various measures of satisfaction. 9

In this sense, the qualitative assessment of Clark County's mental health delivery "system" appeared as follows: Program Assessment: Measures of Effectiveness Detector and Provider Assessment: Measures of Satisfaction

Consumer Assessment: Measures of Satisfaction

For purpose of exposition, further methodological analysis will be particularized to each of the three areas identified above.

\section{Program Assessment}

Following the literature review and general measure selection, specific measures of effectiveness were chosen. 10

${ }^{9} \mathrm{Clergymen}$, physicians, and school counselors and principals were surveyed as they were considered to be community "detectors," in the sense that these service people frequently identify people early who need mental health care.

10 The following measures of effectiveness were selected because it was beyond the scope of this study to devise, test and validate measures of effectiveness of general applicability to all agencies. The measures of effectiveness chosen allude to, or are constraints on, program success. In addition, it is the assumption of this committee that the general measures chosen are directly related to program success. 
For the sake of clarity, these measures were categorized into four areas: Staffing, Training and Specialization, Facility, and Program Evaluation.

Staffing - This category included such measures as: 1) number of staff resignations within past year; 2) percentage of treatment staff that hold the various professional and paraprofessional degrees; and 3 ) number of treatment staff.

Training \& Specialization - This category included such measures as: 1) whether agency uses outside consultants and specialists relative to program treatment; 2) whether agency has established regularized, in-service training; and 3) whether agency staff take outside relevant training.

Facility - This category included problems in the physical aspects of the agency.

Program Evaluation - This category included such measures as: 1) whether the agency has an official program evaluator; 2 ) whether the agency has measureable goals and objectives; 3) at what level of program evaluation does the agency function (e.g., efficiency, effectiveness, satisfaction, etc...); 4) what percentage of staff time is devoted to evaluation; 5) whether the agency measures recividism and; 6) whether the agency has a waiting list for its services.

Once having selected the appropriate measures of effectiveness, the measures were placed in question form and 
incorporated into a questionnaire which contained questions from other mental health study areas (e.g., Prevention, Needs Assessment, Finance, etc.). Because of time constraints, it was decided to use a mailed questionnaire for this portion of the study. The questionnaire was pretested by having various mental health agency representatives complete the questionnaire. The results of the pretest were used to establish the final form of the questionnaire (Appendix A).

Completion of questionnaire construction and testing was proceeded by data collection. The population consisted of all Clark County agencies (15) which provided counseling and/or mental health services (to include emergency services). Of these 15 mailed questionnaires, 15 were returned for a $100 \%$ return rate, which is excellent for survey research. Personal interviews were used as a supplementary tool in order to obtain clarification of existing data or to obtain further data.

\section{Detector and Provider Assessment}

Subsequent to the literature review and general measure selection, specific measures of satisfaction applicable to the community detectors (i.e., clergymen, physicians and school counselors and principals) and providers (i.e., private counselors, phychiatrists and psychologists) were selected. Measures of satisfaction selected included: 1) rating of eleven community services as excellent, good, fair, poor, or 
"don't know"; and 2) indication of the most prevalent reason why referrals were not made to these agencies. The latter measure applied only to community detectors.

Completion of the selection of appropriate measures of satisfaction for community detectors and providers was proceeded by placing the measures in question form and incorporating them into questionnaires containing questions from other mental health study areas as well. Because of the time constraints, it was decided to use a mailed questionnaire for this portion of the study also. Pretesting was accomplished by having committee members and HWPC staff examine the questionnaire, and also by having several detectors and provider complete the questionnaire. The results of this pretest were used to establish the final form of the questionnaires (Appendix B).

Three groups of detectors were surveyed for this review: clergymen, physicians, and school counselors and principals. All clergymen, physicians, and schools were sent questionnaires asking for participation. This yielded a population of 110 , 110 , and 49 respectively. Thirty-eight physicians returned questionnaires for a $34 \%$ return rate. Four indicated that they were retired, semi-retired, or in a speciality that did not apply. Thus, 34 physicians completed the questionnaire. These 34 represented 15 different disciplines ranging from plastic surgery to general practice. Thirty-four clergymen replied to the questionnaire for a $31 \%$ return rate. The congregational 
size of this group ranged from 10 to over 1,000. The total number of members represented was 16,986. The average congregation size was 499. Finally, each school district in Clark County was asked to distribute the questionnaire to elementary school principals and to junior and senior high school counselors and/or principals. This yielded a population of 49 . Of these 49 mailed questionnaires, all were returned, for a $100 \%$ return rate.

In 1975 there were 4.5 psychiatrists ( 1.5 at the Mental Health and Family Services Center) and 10 counselors-psychologists practicing in Clark County. Questionnaires were sent to all involved in private practice. Eight questionnaires were returned for a $55 \%$ return rate.

\section{Consumer Assessment}

Following the literature review and general measure selection, specific measures of satisfaction applicable to consumers of the Mental Health and Family Services Center (MH\&FSC) were chosen. ${ }^{11}$ The measures chosen included:

1) how they (the consumers) felt when they first entered the clinic; 2) how they feel now; 3) whether they still have the same problems; 4) whether they are able to handle them

${ }^{11}$ Consumer assessment was confined to the consumers of Mental Health and Family Services Center because other agencies providing counseling care or mental health services had other priority concerns. 
differently now; 5) how they would rate their expectations; 6) whether they would recommend the clinic to their friends; 7) whether they have recommended the clinic to their friends; 8) whether they have seen any other professional before or after visiting the clinic; 9) whether they feel free to discuss their problems with their therapists, and, 10) whether the clinic helped them.

Once having selected the appropriate measures of satisfaction, the measures were then placed in questionnaire form. Because of time constraints, it was decided to use a mailed questionnaire for the study. The questionnaire was pretested by having committee members and staff of MH\&FSC examine the questionnaire, and also by having several current consumers of MH\&FSC complete the questionnaire. The results of the pretest were used to form the final questionnaire (Appendix $C$ ).

Once the questionnaire had been constructed and tested, data collection began. The population consisted of two major groups; current consumer (active) and past consumer (or inactive) of the Mental Health and Family Services Center. Procedures were established for drawing a systematic random sample of active consumers (every 15 th card) from clinic records of MH\&FSC. A systematic random sample yielded 80 names. Of the 80 , the Mental Health and Family Services Center staff eliminated 7 individuals from receiving the questionnaire for therapeutic reasons. Procedures were again designed for filling the vacancies made by the MH\&FSC staff. Of these 80 mailed 
questionaires, 31 were returned for a $39 \%$ return rate.

Due to the larger number of inactive consumers of MH\&FSC, we selected a systematic random sample (every 30 th. card) from clinic records. This yielded a basic sample of 176 inactive consumers who received the questionnaire. These individuals were replaced in the sample. Of the 176 inactive consumers who were mailed questionnaires, 79 were undeliverable, and 17 returned the questionnaire, for a completion rate of $17.5 \%$.

Obviously the researcher cannot claim the sample of current and past consumers of MH\&FSC to be a complete systematic random sample due to the concern by MH\&FSC staff that certain clients should not receive the questionnaire. However, it is believed the results are relatively accurate and representative of the consumer population of the clinic. ${ }^{12}$

Responses to the questions contained on questionnaires mailed to community agencies, detectors, providers, and consumers were hand tabulated on summary tabulation sheets. As this was an exploratory, descriptive study, it was felt that utilization of simple percentage tables would be applicable in presenting the data. All unusual responses and written remarks were recorded and used in the analysis. Data not directly related to the purpose of the research was omitted for the present.

12 The researcher is aware of the non-response bias operating here. However, reduction of non-response bias was beyond resources of researcher. 
CHAPTER IV

\section{RESULTS}

Measures of Effectiveness: Program Assessment

\section{Staffing}

Measures of effectiveness as presented in the following table, were inferred from data gathered primarily from two sources: 1) Questionnaires consisting of a combination of open and closed-ended questions, which were mailed to all Clark County agencies providing counseling and/or mental health care; and 2) a series of follow-up interviews of the agencies designed to supplement or clarify information obtained from the questionnaires. In applying the data derived from the above sources to the evaluation scheme, the researcher obtained the information contained in Table 1 .

The staffing questions regarding the number of treatment staff, and the percentage of staff in each category were examined in aggregate. The underlying assumption was that quality in staff qualifications (as expressed in terms of formal education and training), could be viewed as a continuum, with Category I representing a relatively high degree of training and education. Ideally, quality of staff qualifications should contain a "mix" of the three categories. 
As indicated in Table 1 , the Clark County mental health system, exclusive of private practitioners, contains approximately 217 practicing treatment personnel, distributed accordingly: Category I: 12\%; Category II: 48\%; Category III: 40\%. Although the majority of treatment personnel have graduate or post graduate degrees $(60 \%)$, the lack of standards for a proper "mix" of the categories precludes inferences on the degree of quality of mental health treatment personnel in Clark County . 


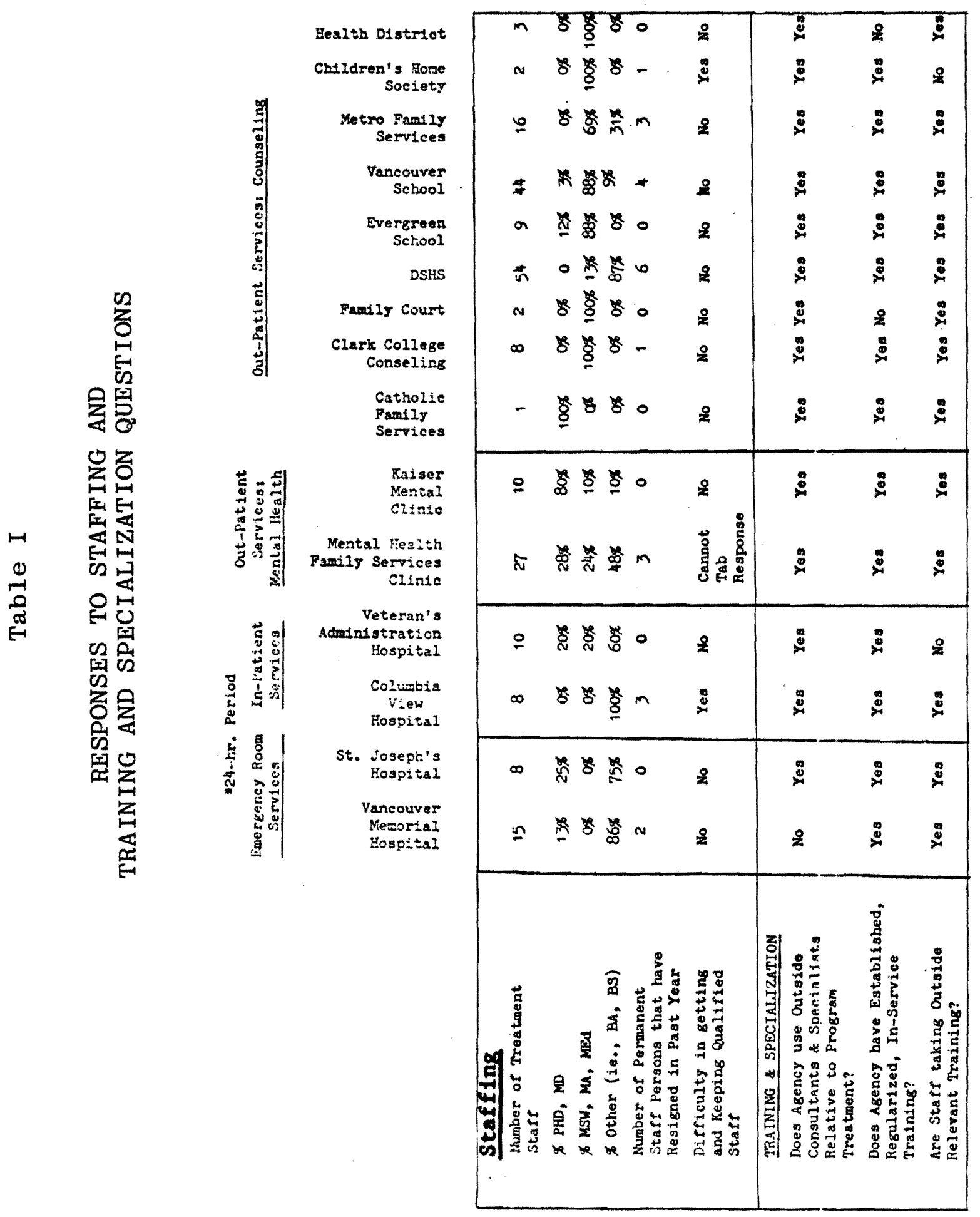


In response to the remaining staffing questions on the number of staff resignations within the past year, an average of 1.6 treatment staff resigned within the past year. This figure indicates an apparently stable working force. In response to the difficulties experienced in retention and recruitment of qualified staff, $86 \%$ (or 12 ) of the agencies surveyed indicated no difficulties and $14 \%$ (or 2 ) indicated some difficulties. Of the $14 \%$ who experienced some difficulties in retention and recruitment of qualified staff, the problem was not internal but external and beyond the agency's control, i.e., the lack of treatment-oriented professionals and the lack of adequate funding to compete with other local areas.

\section{Training and Specialization}

In the face of emerging changes in service delivery patterns to include needs as well as innovative methods and techniques, it is assumed that to facilitate the effective delivery of services, a systematic, periodic utilization of support personnel (i.e., specialists and consultants) is important. In addition, providing an opportunity for staff to increase their sensitivity and professional skills through training is presumed desirable.

Assuming that increased training and utilization of support personnel is conducive to high quality services, the providers of the 15 participating mental health agencies in Clark County were asked the following questions: 1) Do you utilize outside 
consultants and specialists; 2) do you have regularized, inservice training; 3 ) does your staff take outside, relevant training? The preceding table (Table 1) illustrates the responses to these questions.

Of the responding agencies, $93 \%$ (or 14) used outside consultants and specialists, while $88 \%$ (or 13) provided regularized, in-service training in addition to providing staff with an opportunity to take outside training. Thus, the vast majority of the agencies surveyed appeared to adhere to the belief that by providing training to staff, and through the use of consultants and specialists, a higher quality of service could result.

Of those agencies who responded negatively to the question regarding training, it is assumed that their response was indicative of: 1) a lack of resources to provide support personnel and training; 2) support personnel and training not being relevant to their particular program of objectives; or 3 ) rejection of the notion that increased staff training was needed or desired.

\section{Physical Facility}

As identified in the Iiterature, in order to facilitate the delivery of effective mental health services, providers must be responsible for the promotion and development of the physical and social environment of the agency. The latter concept addresses the process of delivering the services in such a manner as to promote an orderly and comfortable atmosphere for 
the consumer. The concept of a physical environment refers to not only meeting the minimum local, state and federal requirements pertaining to health, safety, and sanitation, but to preserving the comfort and privacy of both the providers and the consumers of the service. Acting in concert, social and physical environments should aid in the development of a positive consumer self-image and should preserve their dignity.

Due to resource limitations, and the difficulty in measuring the "quality" of the social environment, the researcher limited his inquiry to the physical environment by asking the service providers to give a brief description of any problems they experienced in their physical plant. The following table (Table 2) illustrates responses relative to the question pertaining to the physical plant. 


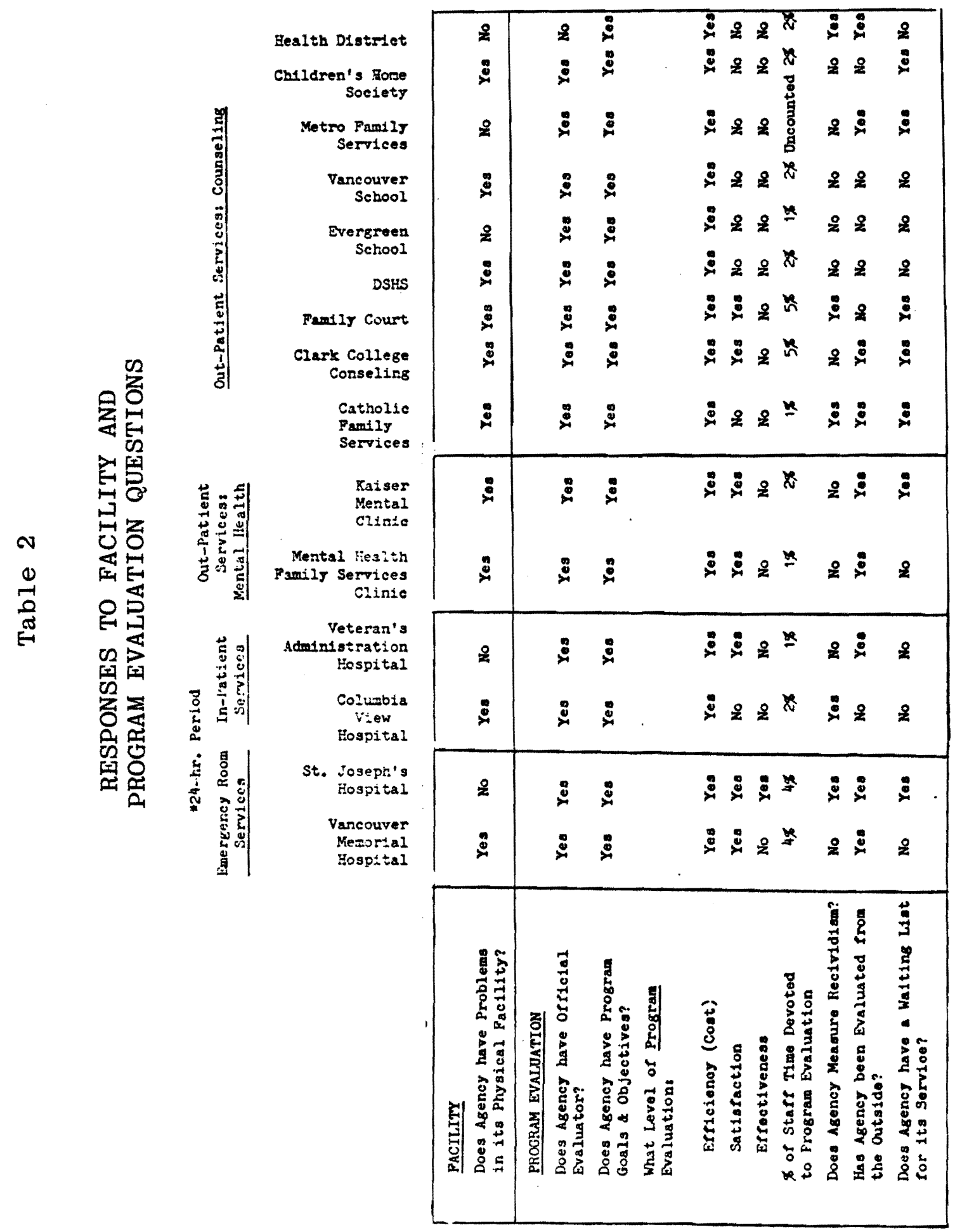


Of the responding agencies, 10 (or 66\%) experienced some problems in their physical plant; 5 (or 33\%) stated they had no problems. Of the agencies who experienced problems, the problems ranged from transportation and access (i.e., parking and location) to delivery of services (i.e., privacy of the consumer/provider relationship). Although the agencies identified the deficiencies in their physical plants, correction of noted deficiencies was essentially beyond the control of the agency. The majority of agencies who experienced problems in their physical plant indicated that limited funding prevented the improvement of their physical plant at this time. The high percentage of agencies indicated problems in their physical plant, and the apparent inability to correct the deficiencies, suggests that Clark County's physical facilities for mental health services, as one determinant of quality, is an area of concern.

\section{Program}

The increasing demand that all social institutions or sub-systems (which includes mental health services) provide "proof" of their legitimacy and effectiveness in order to justify continued support is founded, according to Edward Suchman, on three highly significant societal trends. First, social problems are becoming increasingly more visible and are recognized as effecting the entire community, not just a specific segment within the community (e.g., the minority 
problem). This represents a significant shift in public thought, for it is based on the assumption that social institutions rather than the individual are responsible for social problems and are instrumental in the amelioration of the problem. Second, as a result of the trends in social problems, the nature and scope of public service programs are widening to include services for whole segments of the population. Third, the needs and expectations of the public have changed to include defining services as public rights rather than individual privileges, while simultaneously increasing the demand for accountability of public services through "scientific" proof of the effectiveness of various services.13

Thus, trends in the nature of social problems, functioning of social service programs, and changing public needs and expectations create a growing demand for evaluative research. This growing demand for evaluation of social service programs constitutes the rationale for this section.

In examining the data as contained in Table 2 program evaluation shall be used to refer to the degree to which a program is functioning as it is intended. In contrast, consumer evaluation refers to the effect of the service on the individual client's phychological and social functioning. In other words, program evaluation examines the program in the

${ }^{13}$ Suchman, Evaluative Research, p. 2-6 
aggregate sense while consumer evaluation examines the individual's progress in relation to the program.

As illustrated in Table 2 , all surveyed agenices indicated that some type of program evaluation was being conducted. However, upon closer examination, the evaluation was primarily restricted to measures of efficiency, focusing on managerial or administrative functions. Activities related to statistical descriptions of clients, accounting for expenditures of funds and staff effort, and cost-finding were identified as constituting program evaluation.

In addition to measuring efficiency, $46 \%$ (or 7 ) of the agencies surveyed also measured consumer satisfaction, although this was usually sporadic and with little consistency. For example, suggestion boxes, telephone surveys, and verbal feedback were commonly employed, often on a one-shot basis, as instruments to measure consumer satisfaction.

The measures of efficiency and satisfaction are limited, for other aspects of the program evaluation are valid in assessing the impact of a program. Measures of effectiveness are most important. They include both measures of success and measures of performance, such as treatment outcome. Preconditions for the assessment of program effectiveness include gathering information on the number of patients cured or rehabilitated, collecting data on recividism, and determining measurable goals and objectives. 
Table 2 illustrates that 14 (or 93\%) of the agencies surveyed did not measure the effectiveness of their program. In addition, $66 \%$ ( 10 agencies) failed to measure recividism. Although all agencies had articulated goals and objectives, they were very general and not easily quantifiable or measurable. For example, the goal of assisting families in planning post-hospital care lacks measurable qualities to determine whether or not the goal was reached. The general lack of measuring effectiveness represents a fundamental limitations in the Clark County mental health system, for it raises serious questions of accountability for assumptions underlying the various mental health programs. Specifically, questions of impact cannot be substantiated by $93 \%$ of the agencies because they do not do impact evaluation.

Two other questions which can affect quality were asked of the respondents as an exploratory move. These questions asked if there was a waiting list for their services, and if the agency had been evaluated in the last 5 years from an outside source. Seven of the responding fifteen agencies (46\%) indicated that there was a waiting list for services. This indicates that the demand for services exceeds the supply, that people feel that particular service is more valuable or effective than other services, that people feel that it is an appropriate service. Six agencies (40\%) indicated that no outside evaluation took place in the last 5 years. The remaining 9 agencies (60\%) had evaluations, which were usually audits and 
should be considered business or administrative evaluations.

Measures of Satisfaction: Mental Health and Family Services Center Consumer Assessment

Active Demographic Characteristics

In all characteristics, other than sex ratio and employment, the active consumer appeared to be an accurate representa-. tion of the active consumer of MH\&FSC. Twenty-four females and 7 males returned questionnaires, reflecting a significantly larger number of females in the respondent group. All other characteristics were similar to MH\&FSC demographic characteristics. Three percent of the active consumers were less than 6 years old, $6 \%$ were from 7 to $18,44 \%$ were from 19 to $30,29 \%$ were from 31 to 50 and $17 \%$ were 51 or older. The majority of respondents were divorced (36\%), 26\% were never married, $16 \%$ were married, $16 \%$ were separated, and $6 \%$ widowed. The majority of the respondents $(46 \%)$ had a high school education, $21 \%$ had some college, $15 \%$ had a college degree and $18 \%$ had less than a high school education. Almost half the sample were now working (45\%), 34\% were housewives, $14 \%$ were students, and $7 \%$ were unemployed.

This brief description of the active consumer sample is presented to give the reader an understanding of the respondents. For this report, the data presented will be in terms of modalities. Future analysis may break the active consumer sample into smaller sub-groups, but a general picture of the active consumer 
can be given as: Female, between the ages of 19 and 39, high school educated, and either divorced or never married.

\section{Inactive Demographic Characteristics}

With the relatively high percentage of females in the active group $(77 \%)$, the researcher was not surprised to find that $82 \%$ of the inactive consumer sample were female and $18 \%$ were male. The majority of the males and females (59\%) were between the ages of 31 to 50, with the remaining 7 persons fairly evenly divided in the age categories of 19 to 30 (18\%) and over $50(23 \%)$. The marital status of the respondents was also distributed fairly evenly: Never married - 12\%, married $-29 \%$, remarried $-24 \%$, and divorced - 35\%. The majority of the respondents (53\%) had a high school degree, $12 \%$ had some college education, $6 \%$ had a college degree and $29 \%$ had less than a high school degree. More than half the respondents $(62 \%)$ were now working and $38 \%$ were housewives.

In summary, the inactive consumers of MH\&FSC who returned the questionnaire were females between the ages of 31 and 50. They were married at some time, with at least a high school education, and were either working or a housewife. With this brief description an analysis of the remaining data follows.

\section{Data Presentation}

Table 3 describes the consumers' (active and inactive) feelings when they first sought help at MH\&FSC. Because of the 
small sample size, statistical significance between the active and inactive consumers in any category was not achieved, yet it did appear that there was a pattern in the responses. In all cases the active consumers were generally less "inadequate", "bad", "upset", "fearful," and more "calm" and "confident" than the inactive consumers.

\section{TABLE 3}

MEMORIES OF CONSUMERS REGARDING FEELINGS AT TIME OF INITIAL VISIT TO MH\&FSC

\begin{tabular}{|c|c|c|}
\hline Feelings & $\begin{array}{l}\text { *Average Rank ( } 0 \text { to } 5) \\
X=\text { Active } 0=\text { Inactive } \\
\end{array}$ & Total Response \\
\hline Inadequate & $\begin{array}{l}X=4.0 \\
O=4.09\end{array}$ & $\begin{array}{l}X=25 \\
O=11\end{array}$ \\
\hline Bad & $\begin{array}{l}X=3.45 \\
0=3.62\end{array}$ & $\begin{array}{l}X=20 \\
0=11\end{array}$ \\
\hline Upset & $\begin{array}{l}X=3.96 \\
0=3.90\end{array}$ & $\begin{array}{l}X=25 \\
0=10\end{array}$ \\
\hline Fearful & $\begin{array}{l}X=3.75 \\
O=3.88\end{array}$ & $\begin{array}{l}X=25 \\
O=9\end{array}$ \\
\hline CaIm & $\begin{array}{l}X=2.15 \\
O=1.85\end{array}$ & $\begin{array}{l}X=19 \\
0=7\end{array}$ \\
\hline Confident & $\begin{array}{l}X=2.31 \\
0=1.71\end{array}$ & $\begin{array}{l}X=19 \\
O=7\end{array}$ \\
\hline
\end{tabular}

*1 represents strongly disagree,

5 represents strongly agree

Having described how they felt when they first came to the center, the questionnaire then asked the consumers how they felt now. Table 4 summarizes the way the consumers generally felt at the time of this survey. 
As illustrated by Table 4 there appear to be no discernable difference between the perceptions of the active and inactive consumers. For example, although the actives were less "inadequate", "upset," and more "confident", the inactives were less "bad", "fearful", and more "calm" than the actives.

\section{TABLE 4}

MEMORIES OF CONSUMERS REGARDING FEELINGS AT
THE TIME OF THIS SURVEY

\begin{tabular}{|c|c|c|}
\hline Feelings & $\begin{array}{l}\text { *Average Rank }(0 \text { to } 5) \\
\text { X=Active } \quad 0=\text { Inactive }\end{array}$ & Total Response \\
\hline Inadequate & $\begin{array}{l}X=2.33 \\
O=2.88\end{array}$ & $\begin{array}{l}X=21 \\
0=9\end{array}$ \\
\hline Bad & $\begin{array}{l}X=2.20 \\
O=2.14\end{array}$ & $\begin{array}{l}X=20 \\
O=15\end{array}$ \\
\hline Upset & $\begin{array}{l}X=2.40 \\
0=2.87\end{array}$ & $\begin{array}{l}X=20 \\
0=8\end{array}$ \\
\hline Fearful & $\begin{array}{l}X=2.38 \\
O=2.16\end{array}$ & $\begin{array}{l}X=21 \\
O=6\end{array}$ \\
\hline Calm & $\begin{array}{l}X=3.91 \\
0=3.85\end{array}$ & $\begin{array}{l}X=24 \\
0=7\end{array}$ \\
\hline Confident & $\begin{array}{l}X=3.63 \\
O=3.70\end{array}$ & $\begin{array}{l}X=22 \\
O=7\end{array}$ \\
\hline
\end{tabular}

\footnotetext{
*1 represents strongly disagree

5 represents strongly agree
}

Table 5 indicates the mean improvement from the initial visit to the time of the questionnaire. Actives and inactives improved in all categories. 
TABLE 5

MEAN IMPROVEMENT OF ACTIVE AND INACTIVE FROM INITIAL VISIT TO TIME OF QUESTIONNAIRE

\begin{tabular}{lcc} 
Feelings & Active & Inactive \\
\hline Inadequate & 1.67 & 1.21 \\
Bad & 1.25 & 1.48 \\
Upset & 1.55 & 1.03 \\
Fearful & 1.37 & 1.72 \\
Calm & 1.76 & 2.00 \\
Confident & 1.32 & 1.99
\end{tabular}

Firm conclusions cannot be drawn from the data presented in Tables 4 and 5 . Further studies should be undertaken to discern whether these preliminary findings are further confirmed. These findings suggest:

1. The actives appeared to be in a "better" state of adjustment at their initial visit than the inactives.

2. Both groups improved from initial visit to the time of the questionnaire, however, the inactives had a greater average of improvement than did the actives in all but 2 of the categories.

3. Differences between inactives and actives at the time of the questionnaire were mixed, with no strong trend.

Table 6 presents the data the consumers gave relative to the status of the problems they entered the center with, and their current ability to cope with these problems. As 
illustrated in the table, $60 \%$ of the active consumers and $58.8 \%$ of the inactive consumers indicated the presence of the same problem(s). When asked their current ability to cope with these problems, $86.6 \%$ of the active consumers and $64.7 \%$ of the inactive consumers indicated that they were able to control the problems differently.

TABLE 6

PERCEPTIONS OF THE CONSUMERS REGARDING THE STATUS OF THEIR PROBLEM(S)

Have same problem(s) they entered MH\&FS with:

Yes

Active:

Inactive:

No

$60 \% * \quad 40 \%$

$\mathrm{N}=18 \quad \mathrm{~N}=12$

$58.5 \% \quad 41.1 \%$

Able to handle

differently now:

Yes No

$\mathrm{N}=10 \quad \mathrm{~N}=7$

$86.6 \% \quad 13.3 \%$

$\mathrm{N}=26 \quad \mathrm{~N}=4$

$64.7 \% \quad 34.3 \%$

$\mathrm{N}=11 \quad \mathrm{~N}=6$

*In this and all subsequent tables, the percentages
may not equal exactly $100 \%$ due to rounding error.

The lack of discernable difference between the active and inactive consumers in regards to experiencing the same problem(s), and the apparent statistical difference between the current ability on behalf of both groups to handle the problem(s) $21 \%$ of the actives were better able to handle the problems than the inactives), leads to 2 possible conclusions: 1) active participation in the program has temporary benefits and does 
not have long term effects on behalf of the participants; and 2 ) inactives, upon finding that the service does not help them cope with their problems, drop out.

Turning to consumer expectations, the data presented in Table 7 is collapsed for this discussion in 2 categories:

1) met expectations, which contains the responses of "completely meeting consumer expectations" or "meeting them quite a bit"; and 2 ) did not meet expectations, which contains responses to "meeting expectations very little" or "not at all". The "don't know" category shown in Table 7 was considered not significant and thus omitted for the present.

\section{TABLE 7}

RATING OF CONSUMER EXPECTATIONS REGARDING SERVICES RECEIVED AT MH\&FSC

Expectation

Completely met my expectations

Met it quite a bit

Don't know

Met my expectation very little

Did not meet it at al1

\begin{tabular}{ll}
\multicolumn{2}{c}{ Response } \\
$=8$ & Inactive \\
$\mathrm{N}=8$ & $\mathrm{~N}=4$ \\
$\mathrm{~N}=16 \%$ & $25 \%$ \\
$51.6 \%$ & $\mathrm{~N}=6$ \\
$\mathrm{~N}=2$ & $37.5 \%$ \\
$6.4 \%$ & $\mathrm{~N}=2$ \\
$\mathrm{~N}=4$ & $12.5 \%$ \\
$12.9 \%$ & $\mathrm{~N}=2$ \\
$\mathrm{~N}=1$ & $12.5 \%$ \\
$3.2 \%$ & $\mathrm{~N}=2$ \\
& $12.5 \%$
\end{tabular}


As illustrated, $77.4 \%$ of the active consumers and $62.5 \%$ of the inactive consumers had their expectations met to some degree, while $16.1 \%$ of the actives and $25 \%$ of the inactive consumers indicated some degree of failure in reaching their expectations. This would suggest that active consumer expectations, as one indicator of consumer satisfaction, appeared to be more satisfied with the services received than the inactive group. However, it is presumed that this response is consistant with the active status.

Another indicator of consumer satisfaction is illustrated in Table 8. Except for the categories of "reasonable fees", "distance from home", and "waiting time", the active consumers were more favorable disposed to certain characteristics of MH\&FSC than were inactive consumers. The negligible or slight difference noted in these exceptions may be attributed to a time variable which might confuse the situation. 
TABLE 8

RATING BY CONSUMERS REGARDING SELECT CHARACTERISTICS OF MH\&FSC

Feelings *Average Rank ( 0 to 7 ) $\mathrm{X}=$ Active $\quad 0=$ Inactive

Total Response (N's)

\begin{tabular}{|c|c|c|}
\hline Friendly staff & $\begin{array}{l}X=6.35 \\
O=5.6\end{array}$ & $\begin{array}{l}X=31 \\
0=15\end{array}$ \\
\hline Appropriate dress & $\begin{array}{l}X=6.03 \\
O=5.76\end{array}$ & $\begin{array}{l}x=31 \\
0=16\end{array}$ \\
\hline Comfortable setting & $\begin{array}{l}X=4.7 \\
O=4.58\end{array}$ & $\begin{array}{l}X=30 \\
O=17\end{array}$ \\
\hline Flexible hours & $\begin{array}{l}X=5.6 \\
0=5.37\end{array}$ & $\begin{array}{l}X=30 \\
O=17\end{array}$ \\
\hline Staff "on time" & $\begin{array}{l}X=5.80 \\
O=5.52\end{array}$ & $\begin{array}{l}X=31 \\
0=17\end{array}$ \\
\hline Reasonable fees & $\begin{array}{l}X=6.43 \\
O=6.43\end{array}$ & $\begin{array}{l}X=31 \\
0=16\end{array}$ \\
\hline Easy to talk to & $\begin{array}{l}X=6.12 \\
0=5.68\end{array}$ & $\begin{array}{l}X=31 \\
0=16\end{array}$ \\
\hline Choice of treatment & $\begin{array}{l}X=5.87 \\
O=4.53\end{array}$ & $\begin{array}{l}X=31 \\
O=15\end{array}$ \\
\hline Helped with problems & $\begin{array}{l}X=6.16 \\
O=4.94\end{array}$ & $\begin{array}{l}x=31 \\
0=17\end{array}$ \\
\hline Good location & $\begin{array}{l}X=4.76 \\
O=4.62\end{array}$ & $\begin{array}{l}X=30 \\
O=16\end{array}$ \\
\hline Not too far from home & $\begin{array}{l}X=5.06 \\
O=5.43\end{array}$ & $\begin{array}{l}X=30 \\
0=16\end{array}$ \\
\hline Short waiting time & $\begin{array}{l}X=5.63 \\
0=6.0\end{array}$ & $\begin{array}{l}X=30 \\
0=16\end{array}$ \\
\hline Highly skilled staff & $\begin{array}{l}X=6.16 \\
O=5.12\end{array}$ & $\begin{array}{l}X=30 \\
O=16\end{array}$ \\
\hline
\end{tabular}

* I represents strongly disagree

7 represents strongly agree 
The data presented in Tables 7 and 8 leads to the following hypotheses: 1) current program participation yields more favorable perceptions than past program participation; or 2) people drop out of the program because of unfavorable attitudes toward it. Both hypotheses should be tested vigorously in the future.

The survey inquired about the satisfaction issue by asking the consumers, "Would you recommend the center to your friends," and, Have you recommended the center to your friends?" A sizable majority of the active consumers (93.3\%) said they would recommend the center, while $80.8 \%$ said they have recommended it. In contrast, $80 \%$ of the inactive consumers said they would recommend the center, and $52.9 \%$ said they have recommended it. Table 9 illustrates the responses.

TABLE 9

CONSUMERS' RESPONSES REGARDING

RECOMMENDATIONS OF MH\&FSC

\begin{tabular}{|c|c|c|c|c|}
\hline & \multicolumn{2}{|c|}{ Would recommend } & \multicolumn{2}{|c|}{ Have Recommended } \\
\hline & yes & no & yes & no \\
\hline Active: & $\begin{array}{l}N=28 \\
93.3 \%\end{array}$ & $\begin{array}{l}N=2 \\
6.6 \%\end{array}$ & $\begin{array}{l}N=55 \\
80.8 \%\end{array}$ & $\begin{array}{l}N=13 \\
19.1 \%\end{array}$ \\
\hline Inactive: & $\begin{array}{l}N=12 \\
80 \%\end{array}$ & $\begin{array}{l}\mathrm{N}=3 \\
20 \%\end{array}$ & $\begin{array}{l}N=9 \\
52.9 \%\end{array}$ & $\begin{array}{l}N=8 \\
47.1 \%\end{array}$ \\
\hline
\end{tabular}


When asked if they had seen any other agency or professional helping person prior or since their visit to the center, the response patterns of the 2 groups varied, as summarized in table 10:

\section{TABLE 10}

CONSUMERS RESPONSES CONCERNING SEEKING HELP FROM OTHER PROFESSIONAL OR AGENCIES PRIOR OR SINCE VISITATION TO MH\&FSC

\begin{tabular}{|c|c|c|c|c|}
\hline & \multicolumn{2}{|c|}{$\begin{array}{l}\text { Sought help } \\
\text { Prior }\end{array}$} & \multicolumn{2}{|c|}{$\begin{array}{l}\text { Sought help } \\
\text { Since }\end{array}$} \\
\hline & yes & no & yes & no \\
\hline Active: & $\begin{array}{l}N=19 \\
61.29 \%\end{array}$ & $\begin{array}{l}N=12 \\
38.7 \%\end{array}$ & $\begin{array}{l}N=5 \\
16.6 \%\end{array}$ & $\begin{array}{l}N=25 \\
83.3 \%\end{array}$ \\
\hline Inactive: & $\begin{array}{l}N=8 \\
47.1 \%\end{array}$ & $\begin{array}{l}N=9 \\
52.9 \%\end{array}$ & $\begin{array}{l}N=4 \\
25 \%\end{array}$ & $\begin{array}{l}N=12 \\
75 \%\end{array}$ \\
\hline
\end{tabular}

Approximately half (52.9\%) of the inactives were not seen by other agencies or professionals prior to their first visit to the center. On the other hand, $61.2 \%$ of the actives did see other agencies or professionals prior to their first visit to the center. When asked if other agencies or professionals have been seen since they visited the center (a possible indicator of dissatisfaction), $16.6 \%$ of the actives as well as $25 \%$ of the inactives sought further agency or professional services. As for the $75 \%$ of the inactives and $83.3 \%$ of the active consumers who have not sought further services, it can be assumed that both groups: 1) May have been helped by MH\&FSC; 2) became dissatisfied with any type of professional help, or 3) were 
helped through other means.

Table 11 summarizes the consumers' attitudes towards therapist interaction. The overwhelming majority of the active group (95.8\%), and a slightly smaller number of the inactive group ( $82.3 \%)$, felt that the therapist interaction was unrestricted.

TABLE 11

CONSUMERS' RESPONSE REGARDING THERAPISTS INTERACTION

\begin{tabular}{ll}
$\begin{array}{l}\text { Unrestricted } \\
\text { Interaction }\end{array}$ & $\begin{array}{l}\text { Restricted } \\
\text { Interaction }\end{array}$ \\
\hline
\end{tabular}

Active:

Inactive:
$95.8 \%$

$\mathrm{N}=23$

$82.3 \%$

$\mathrm{N}=14$
$4.1 \%$

$\mathrm{N}=1$

$17.6 \%$

$\mathrm{N}=3$

The final question, as presented in Table 12 below, asked the consumers their perception of how useful the center was. $90.32 \%$ of the active group and $70.58 \%$ of the inactive group indicated that the center did indeed help them.

TABLE 12

CONSUMERS' RESPONSE CONCERNING USEFULNESS OF MH\&FSC Center helped Center did not help

$\begin{array}{lll}\text { Active } & 90.32 \% & 9.67 \% \\ & \mathrm{~N}=28 & \mathrm{~N}=3 \\ \text { Inactive } & 70.58 \% & 29.41 \% \\ & \mathrm{~N}=12 & \mathrm{~N}=5\end{array}$


The responses as shown in Tables 11 and 12 would appear to support the previously advanced hypotheses that indeed the active status may be an influential factor in perception or memories of the program and that inactive status may represent dissatisfaction with the program. Both hypotheses should be tested vigorously in the future.

Comparison of the Active and Inactive Consumers:

The background data of the active and inactive consumers illuminates some important differences between the two major samples. Aside from the obvious differences in status (active versus inactive), there were other distinctions. The active consumer tended to be younger, normally falling between the ages of 19 to 30 , whereas the inactive consumer fell between the ages of 31 to 50 . Both groups were predominantly female and tended to have at least a high school education. The researcher found no discernable difference between the 2 sample groups regarding marital and occupational status.

The active group's memory regarding their feelings at the time of their initial visit to the center tended to reflect a "better" state of adjustment than the memory of the inactive group. Yet, when asked an identical attitudinal question regarding their current state of adjustment, there was no discernable difference between the responses of the 2 groups. 
Both groups agreed that they currently have the same problems that they entered the center with. However, the active group felt that they had the ability to handle or cope with these problems to a significantly larger degree than the inactive group.

Proportionately equal numbers of both groups (25\%) rated the treatment received at the center as completely meeting their expectations. In addition, more actives than inactives reported their expectations as being met almost completely.

The active group's perceptions tended to be more favorably disposed toward the center's characteristics (e.g., staff, setting, treatment, etc.) than the inactive group. Not surprisingly, more actives than inactives have, or would, recommend the center to their friends.

A greater majority of the active consumers sought other agency or professional services prior to seeking help at MH\&FSC. In contrast, a larger number of inactive consumers sought additional services after first visiting the center. This response would appear to question the accuracy or truthfulness of the perceptions of the active consumers relative to their state of adjustment at the time of the initial visit to the center. Their perceptions or memories may be clouded by their present generally good feelings toward MH\&FSC.

There were some differences in the perception of both groups regarding interaction with the therapist. Generally, more active consumers than inactive consumers felt interaction 
with the therapist was relatively unrestricted and more open. This may be one explanation of why inactives discontinued service at the center, and would appear to be consistant with response patterns previously established by both groups.

When asked if the MH\&FSC helped them, the active group expressed a more positive attitude of the center's usefulness to them. This would again appear to be consistent with the response pattern previously established by both groups.

The exploratory and descriptive nature of the consumer assessment, the lack of supportive statistical indices or "proofs", and the inability to account for the non-response bias precludes the absolute validation of these theories or hypotheses. Rather, this study was designed to: 1) tease out possible hypotheses which require vigorous future testing; 2) provide more information about the consumers of one particular agency (MH\&FSC) than we now have; and 3 ) act as a pilot study to enable other human service organizations to assess consumer satisfaction.

The following hypotheses were derived from the consumer study of MH\&FSC, and are submitted for consideration and future testing:

1. Active program participation yields more favorable perceptions of the program than inactive program participation.

2. Active participation, in MH\&FSC may have only temporary benefits at best, and may not have long-term effects for a significant proportion of consumers. 
3. The nature of services provided may produce a dependency relationship between the client and the service providers at the center.

Measures of Satisfaction: Detector and Provider Assessment

Measures of satisfaction relative to community detectors and private practice providers were inferred from data gathered primarily from questionnaires which were mailed to many of the community detectors and private practice providers.

Table 13 presents the composit responses of the detectors and providers responding to the question of rating various community mental health services ( $N=101$ except as noted). The average responses specific to each service are placed at the end of the row. The aggregate responses specific to each respondent can be read at the bottom of each response category.

In analyzing the data we established two sets of criteria: 1) responses which were $50 \%$, or in excess of $50 \%$, were considered significant; and 2) responses, regardless of percentile, were examined in order to identify any discernable patterns or groupings. These criteria were selected for analyzing detector and provider data because they are traditionally acceptable as arbitrary units, and because we had no other information on which to base other arbitrary standards.

As a group (the smallest), private counselors, psychiatrists, and psychologists tended to be more favorably disposed 
toward rating the majority of services ( 6 out of 10 ) as being either good or excellent. This was derived from using the standard of $50 \%$ as constituting a signficant response. In contrast, significantly fewer services were ranked good or excellent by other respondents. In terms of the most favorable response, only one category--private counselors and psychologists--received a response percentage of $50 \%$ or greater from more than one group. From this data it would appear that private counselors and psychologists are, held by most, in a higher regard in this community than other mental health services professionals.

As illustrated by the "don't know" category, the clergymen and private counselors, psychiatrists, and psychologists appear to be more familiar with various community mental health services than school counselors and principals and physicians. Catholic Family Counseling Center and Children's Home Society of Washington were identified as the least visible by the respondents, followed by Kaiser Mental Health Clinic, Southwest Washington Health District, and Clark County Family Court. Limited communication between community detectors and providers and community services, or distorted knowledge of available services may be possible explanations for the lack of visibility of a majority of community mental health services. 


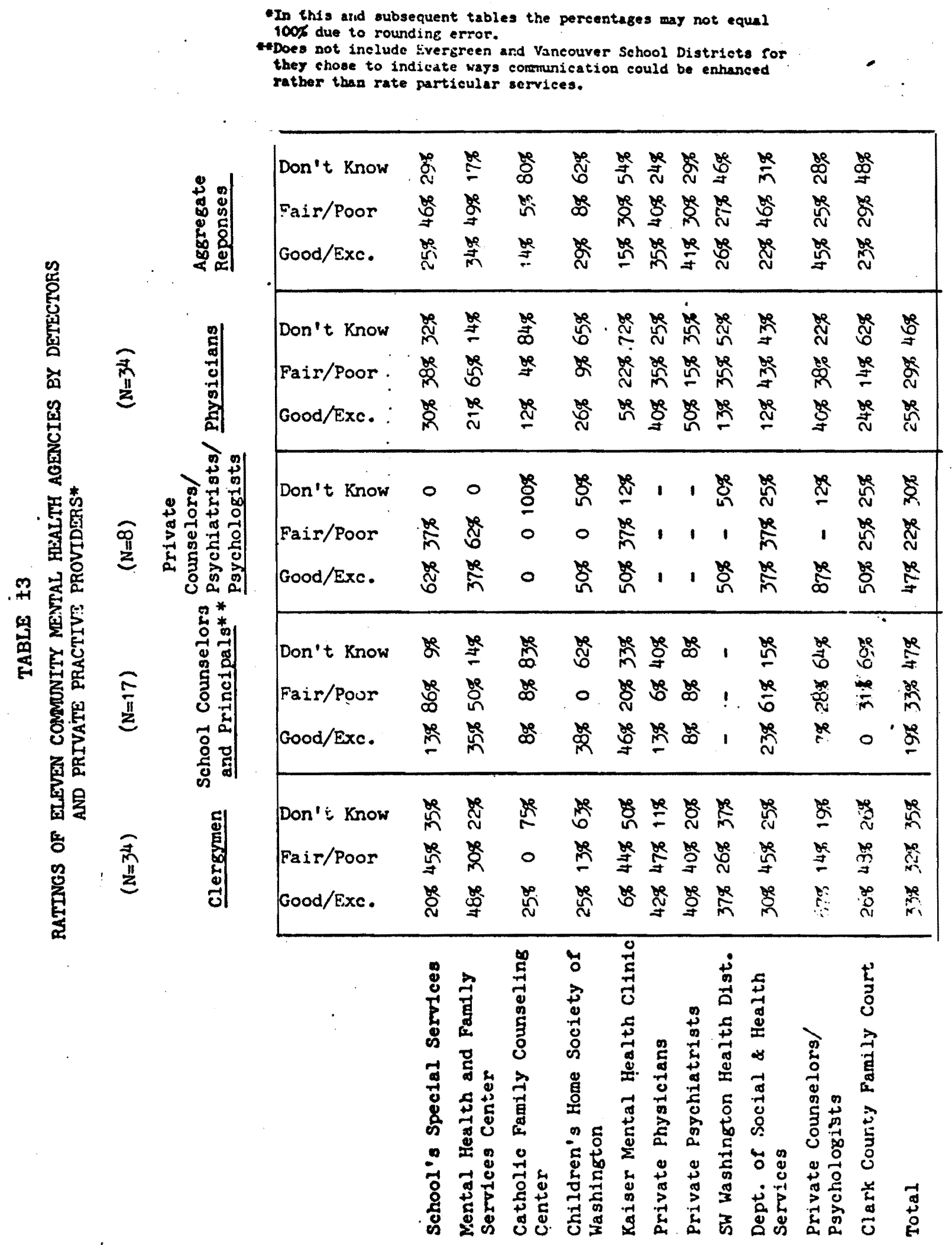


Better than one-fourth of the services listed received a fair or poor rating from school counselors and principals (excluding Evergreen and Vancouver School Districts). A pattern developed primarily among clergymen who rated six services within eight percentage points of $50 \%$ as "fair or poor." While it did not reach the $50 \%$ criterion it was considered significant.

Addressing particular services, The Mental Health and Family Services Center was identified by 3 out of 4 respondent groups as being "fair or poor." School Special Services and the Department of Social and Health Services were identified by at least one responding group as being "fair or poor."

In the aggregate, of the eleven mental health agencies or professional groups, private counselors, psychologists, and psychiatrists were close in ranking, more frequently seen as providing "good or excellent" mental health services. The consensus among the respondents appeared to be: 1) There is a general lack of knowledge about services, particularly Catholic Family Counseling Center, Kaiser Mental Health Clinic, and S.W. Washington Health District; and 2) there were less positive reactions to Mental Health and Family Services Center, School Special Services, and the Department of Social and Health Services. 
Analyzing the response patterns of particular respondent groups, the private counselors, psychiatrists, and psychologists appear to be more favorable disposed and familiar with various community mental health services than other respondent groups. In contrast, school counselors and principals appeared to be the most critical and least familiar with services. Physicians ranked very close to school counselors and principals in being least familiar with services.

Although Evergreen and Vancouver School Districts chose to indicate ways to enhance communication between service providers and community detectors, it was possible to discern patterns or groupings of responses relative to program effectiveness. In the aggregate, the majority of Evergreen and Vancouver School District respondents reflected concern for the lack of information regarding particular programs, eg., Catholic Family Counseling Center, Children's Home Society, and SW Washington Health District were identified by most respondents as being least visible in terms of information available. Correspondingly, the Vancouver and Evergreen School District respondents recommended establishing a "feedback" system between community service providers and detectors. 
TABLE 14

RANKING OF MOST PREVALENT REASONS BY DETECTORS

FOR NOT REFERRING TO COMMUNITY MENTAL HEALTH AGENCIES

\begin{tabular}{|c|c|c|c|c|}
\hline Rank & Reasons & Clergy & Physicians & $\begin{array}{l}\text { School Coun. } \\
\text { Principals }\end{array}$ \\
\hline 1. & $\begin{array}{l}\text { Unfamiliar with some } \\
\text { agency's programs }\end{array}$ & 1 & 2 & 1 \\
\hline 2 . & $\begin{array}{l}\text { It is suspected that } \\
\text { clients will not } \\
\text { follow-up on re- } \\
\text { ferral }\end{array}$ & 2 & 4 & 2 \\
\hline 3. & $\begin{array}{l}\text { Poor results from } \\
\text { previous referrals }\end{array}$ & 5 & 1 & 5 \\
\hline 4. & Cost is excessive & 4 & 7 & 6 \\
\hline 5. & $\begin{array}{l}\text { Long waiting list at } \\
\text { some agencies }\end{array}$ & 9 & 5 & 4 \\
\hline 6. & $\begin{array}{l}\text { Client prefers private } \\
\text { psychiatrist/phy- } \\
\text { chologist }\end{array}$ & 6 & 3 & 8 \\
\hline 7 . & $\begin{array}{l}\text { Image of agency as } \\
\text { "serving the poor" }\end{array}$ & 8 & 6 & 9 \\
\hline 8. & Anti-religious & 3 & - & - \\
\hline 9 . & $\begin{array}{l}\text { Schools Special Ser- } \\
\text { vices handles all } \\
\text { cases }\end{array}$ & - & - & 3 \\
\hline 10. & Other & 7 & 8 & 6 \\
\hline
\end{tabular}

For the sake of simplicity, percentages for each response are not provided. Instead the researcher summed the ranks and ranked the sums for each response. Rank I is the most prevalent reason why referrals to community agencies are not made and Rank 9 is the least prevalent reason. 
Table 14 presents the data respondent groups gave concerning the reasons for lack of referrals to community agencies. In the aggregate, unfamiliarity with agencies and their programs was identified by the respondents as being the most prevalent reason why they do not make community referrals. A close second was the suspicion among respondents (primarily clergymen and school counselors and principals) that the "client will not follow-up." "Poor results from previous referrals" and "excessive cost" ranked three and four respectively. "Long waiting 1ists" and "preference of private psychiatrists and psychologists to public agencies" were ranked next. Finally, an image that the community agency was "serving the poor" was the lease prevalent reason. Responses which were unrankable, in an aggregate sense, because of their specificity to certain detector groups were community agencies with an "anit-religious" orientation (ranked three by clergy), and "School Special Services responsibility for referrals" ranked three by school counselors and principals.

From the data presented in Table 13 and 14 and the responses of the Evergreen and Vancouver School Districts, the following hypotheses were derived:

1. Lack of familarity with mental health services may distort perceptions regarding service effectiveness, and

2. Professional orientation and/or experience may influence perceptions of a particular service.

Both hypotheses require vigorous future testing. 
CHAPTER V

\section{RECOMMENDATIONS}

This study has answered some questions and no doubt raised others, but has indicated that although service providers are concerned with program evaluation, the Clark County mental health delivery system lacks any clear cut, universally accepted set of criteria or standards for assessing and assuring the quality of its services. Therefore the need for some type of quality control becomes critically important. In light of this, the following recommendations are submitted with the intent to establish a data base from which quality can be assessed and assured. For the purpose of exposition, the recommendations are formed into categories, each containing specific recommendations. The categories are: Program, Staff, Physical Facilities and Relationship to the system.

\section{$\underline{\text { Program }}$}

Confirming McIntire's previously noted findings, less than $3 \%$ of staff time was devoted to program evaluation.15

15 McIntire feels that to be useful, evaluative efforts should require from $5 \%$ to $10 \%$ of all staff time. However, nationally, only $2.7 \%$ of staff time has been devoted to evaluation. 
of this, the majority of staff effort was confined to issues such as statistical description of clients, accounting for expenditures of funds and staff effort and the like; issues of satisfaction and effectiveness were generally neglected. In addition, of the agencies surveyed, the majority lacked measurable goals and objectives as well as specific procedures to collect data necessary to evaluate the programs effectiveness (i.e., recividism rates). These phenomena coupled with the general lack of outside evaluations prompts the following recommendations:

1. THE GOALS AND OBJECTIVES OF A PROGRAM NEED TO BE STATED IN SUCH A WAY AS TO DETERMINE THE EFFORTS OF THE PROGRAM AGAINST THE GOALS IT SETS OUT TO ACCOMPLISH.

2. COMPREHENSIVE, OUTSIDE PROGRAM EVALUATION SHOULD BE CONDUCTED EVERY THREE TO FIVE YEARS FOR SMALLER AGENCIES AND YEARLY FOR LARGER AGENCIES. AGENCY SIZE COULD BE DETERMINED IN PART BY STAFF/ CLIENT RATIOS, CATCHMENT AREAS, ETC.

3. BASELINE DATA SHOULD BE ESTABLISHED FROM WHICH THE MENTAL HEALTH SYSTEM AND MEMBER AGENCIES SHOULD BE EVALUATED FOR THE BASIS OF MAKING LONGITUDINAL OR ONE-SHOT COMPARISON STUDIES WITH SIMILAR COUNTIES OR CATCHMENT AREAS.

4. AGENCIES SHOULD SEEK FUNDING FOR TRAINING EVALUATIVE SPECIALISTS AND/OR OBTAINING OUTSIDE EVALUATIVE SPECIALISTS.

\section{Staffing}

Although there was no apparent difficulty in recruitment or retention of qualified staff, and although there was usually relevant ongoing training available (either internally or externally), there was an informal consensus that funding 
for personnel served as a constraint. In addition, Clark County lacks standards for the "proper" proportion of $\mathrm{PhD} / \mathrm{MD} /$ MSW/MA/MED/BS/BA/AA, etc. on treatment staff. Therefore, the researcher recommends:

1. STANDARDS SHOULD BE ESTABLISHED REGARDING THE PROPORTION OF PhD/MD/MSW/MA/MED/BA/BS/AA, AND OTHER DEGREES OR CERTIFICATES ON TREATMENT STAFF.

2. A "TRAINING CONSORTIUM" SHOULD BE ESTABLISHED SO THAT MENTAL HEALTH AGENCIES CAN POOL THEIR RESOURCES, SHARING ADMINISTRATIVE AND OTHER COSTS, TO PROVIDE RELEVANT TRAINING FOR TREATMENT PERSONNEL.

3. A METHODOLOGY SHOULD BE ESTABLISHED TO TEST THE VALIDITY OF THE WIDELY HELD ASSUMPTION THAT INCREASED FORMAL EDUCATION AND TRAINING HAS A POSITIVE EFFECT UPON PROGRAM QUALITY.

4. STANDARDS SHOULD BE ESTABLISHED REGARDING THE ROLE AND FUNCTION OF PARA-PROFESSIONALS ON TREATMENT STAFF.

\section{Physical Facilities}

With approximately $71 \%$ of the agencies surveyed indicating some problems in their physical facility, the researcher recommends:

1. AGENCIES SHOULD COOPERATIVELY OR SINGLY SEEK FUNDING FOR CONSTRUCTION OR IMPROVEMENT OF THEIR PHYSICAL FACILITIES.

\section{Relationship to the System}

The lack of knowledge on behalf of the detectors regarding available community mental health services, and the absence of any standards governing the mental health system has lead the researcher to recommend: 
1. A SINGLE, UNIFORM SET OF STANDARDS SHOULD BE ESTABLISHED TO GOVERN THE PROVISION OF SERVICES TO ALL CONSUMERS OF MENTAL HEALTH SERVICES IN BOTH PUBLIC AND PRIVATE SECTORS IN CLARK COUNTY.

2. ONCE ESTABLISHED, STANDARDS, TO BE MAXIMALLY EFFECTIVE, SHOULD BE ENFORCED THROUGH STRONG ACCREDITATION PROCEDURES GOVERNING THE OPERATION OF CLARK COUNTY'S COMMUNITY MENTAL HEALTH CENTER. THE STANDARDS REVIEW PROCESS SHOULD INCLUDE: CLIENTS, PROVIDERS, PLANNERS AND GOVERNMENT.

3. DEVELOPMENT OF APPROPRIATE CHANNELS OF COMMUNICATION BETWEEN PROVIDERS, DETECTORS AND SUPPORT SERVICE AGENCIES SHOULD BE ESTABLISHED TO INSURE AWARENESS OF AVAILABLE COMMUNITY MENTAL HEALTH PROGRAMS AND SERVICES. SUGGESTED METHODS INCLUDE: FORUMS, INFORMATION PACKETS AND/OR SITE VISITS.

4. A MENTAL HEALTH ASSOCIATION SHOULD BE FORMED, COMPOSED OF VARIOUS MENTAL HEALTH AGENCIES IN CLARK COUNTY AND REPRESENTATIVES FROM THE COMMUNITY AT LARGE. THE RESPONSIBILITY OF THE ASSOCIATION WOULD BE TO MONITOR MENTAL HEALTH SERVICES TO INSURE HIGH QUALITY.

5. ALI AGENCIES SHOULD DEVELOP MECHANISMS TO SYSTEMATICALLY AND PERIODICALLY ASSESS CONSUMER SATISFACTION WITH THE SERVICE OR TREATMENT RECEIVED.

\section{Epilogue}

Within a month after the publication of the Mental Health Study, a series of public meetings and workshops with the Clark County Commissioners were held. The purpose of these meetings and workshops was to acquaint the public and the elected officials with the study:

Following these initial sessions, the Clark County Commissioners requested the Clark County Social Services Administrative Board ( $S S A B$ ) to review the study's findings 
and make recommendations regarding the feasibility of implementing its findings. Because the Social Services Administrative Board was involved in its annual budgetary process, the Commissioner's request was deferred until February, 1976.

In February, 1976 with the budgetary process complete, the SSAB began the task of conducting a study to determine the feasibility of implementing the Mental Health Study's findings. The procedure used by the SSAB was to ask each community detector and provider to indicate their feelings toward each Mental Health Study recommendation as well as to prioritize the six most important. A mailed questionnaire was used to solicit this information with telephone calls used to insure an adequate return rate.

As of March 30,1976 , no questionnaires have been returned. It is proposed that once the questionnaires are returned, the responses will be aggregated and the recommendations ranked. Following this ranking process, the top several recommendations will be examined further by the SSAB with respect to the criteria of cost, sponsorship as well as considering each against existing programs and activities. The surviving recommendations will then be submitted to the Commissioners and will likely serve as a basis for new programs and activities in fiscal year 1977. 


\section{ANNOTATED BIBLIOGRAPHY}

The following bibliography is not intended as a complete guide to all areas of mental health quality assessment. Rather than providing numerous examples of quality assessment approaches and theories, the bibliography is organized to provide information which was instrumental in assessing the quality of Clark County's mental health delivery system.

Akin, Marvin C. "Evaluation through Development," Evaluation Comment, (February 1969): 2-7.

The author identifies five areas of evaluation: 1) Systems Assessment provides information about the state of the system; 2) Program Planning provides information relevant to selection of programs to serve specific needs; 3) Program Implementation provides information about the extent to which a program has been introduced in the intended manner; 4) Program Modification provides help in improving the program; and 5) Program Certification helps decision makers judge the overall worth of a program. The author states that each of these areas require different approaches and methods.

Altman, Isidore. Statistical Approach to Assessing Quality of Medical Care, Washington D.C.: American Statistical Association, 1968.

The author argues that the definition of quality may vary considerably, although it is, ordinarily, a reflection of values and goals current in the medical care system and in the larger society of which it is part.

Another relevant section of this paper deals with selfclassification of evaluation called patient expectations and satisfaction. In short, if a patient is happy about his care or believes he has received good care, then his care has in fact been good. The author feels that this may be one of the most valid ways to measure effectiveness. 
Bahn, Anita K; Kramer, Morton; Locke, Denzi. "The National Approach to the Evaluation of Community Mental Health Programs," American Journal of Public Health. 51 (March 1961): 969-978

One of the factors the authors point to as being instrumental in evaluation is the base-line data needed in any community to establish the impact of various modalities of intervention on mental health levels in the community. For example, changes in the incidence and prevalance of mental disorders may be the first step in an evaluation scheme. The authors also indicate that there are many other factors that should be considered: 1) there are many practical and theoretical problems in the collection and assessment of quantitive measures of the phenomena; 2) there are very few indexes that are generally accepted by various mental health officials as being valid measures of the impact of any program; 3) mental health programs are often instituted without comfort or cushion of the research and validation background (there is no adequate experimentation and information on the effectiveness of the program gathered or derived through carefully designed experimental efforts); and 4) data coordination and data collection mechanisms by which assessment impact of the various programs singly and collectively on the status of mental health in the community is lacking.

Bend, Emil, "The Impact of a Social Setting Upon Evaluative Research," In Evaluative Research: Strategies and methods, pp 109-29. Edited by American Institute for Research. Pittsburgh: American Institute for Research, 1970.

This paper discusses recurring administrative problems in planning and conducting evaluation of social action programs. The evaluation research process is divided into three phases and problems are discussed in each phase: Phase I - The Planning and Preparations Phase. Problems in this phase include inadequate information and differential expectations of sponsors and subjects resulting in a gap between the research and the divergent interests within theorganization. Another problem with this phase in a lack of coordination within and between the organization and the research team which may have unfortunate scheduling and attitudinal consequences. Phase II - The On-Site Phase. Problems in this phase include a lack of acceptance of the research team by the subjects which may result in incomplete, incorrect or biased data. Another problem experienced in phaze II has to do with the evaluation project being jeopardized by the furor of program staff to meet conditions imposed by the research design. Phase III - 
The Analysis and Reporting Phase. Problems of this phase relate to the presentation of findings and recommendations which may be presented in a form that makes them difficult for sponsors to interpret and apply.

Blaine, Howard T.; Hi11, Marjorie, J.; "Evaluation of Phschotherapy with Alcoholics," The Quarterly Journal of Studies on Alcohol 28, (January 1967): 76-104

The authors reviewed 49 different studies with respect to five criteria: 1) use of controls, 2) subject selection procedures, 3) selection and definition of criterion variables, 4) measurement instruments and their reliability, and 5) measurement of before and after treatment.

Chu, Franklin; Trotter, Sharland. Mental Health Complex Part I: Community Mental Health Centers, Washington D.C.: Center for Responsive Law, 1972 .

Prior to the end of World War II, there was no attempt to assess the quality of care provided in the mental health centers or institutions rather, the practice was simply one of a pragmatic yardstick of both cost efficiency as well as the meager yardstick of re-entry into society. No assessment was made as to the qualitative condition of the individual subsequent to the intervention by the mental health professional.

However, some indication that evaluation was on-going during this period is evidenced by David Mechanic in his study "Mental Health and Social Policies." Dr. Mechanic notes that there was a growing realization of a deficiency in mental hespitals in that very often the end result of innovation in mental hospitals was the increased isolation of the patient from this community and any social relations, that there was a retardation of the patients skills and in general an induced level of disability above and beyond that resulting from the patients conditions.

In 1955 Congress established a joint commission on mental illness and health that proposed essentially a massive funding of mental health programming by the federal government and it outlined principles of matching grants to facilitate the federal involvement, and most importantly, it recommended that the awards should be granted according to some criteria of merit and incentive and be formulated by an expert advisory committee appointed by the National Institute of Health. The commission's recommendations were one of the first 
published by such an august body that suggests the federal government should establish and maintain standards for the quality of care in the mental ill.

In May of 1964, federal regulations were issued that attempted to define the operations of the community mental health center, the new mode of mental health provision of services. These regulation could be termed a very tentative first approach to quality of care in that they define the area served by the nature of the center and the services it had to provide. It did not however, get into the technological aspect of program evaluation of quality of care.

Further on the report illuminates one of the factors that have been interfering with quality of care in evaluation and that is simply that the present hierarchy of mental health facilities are doctors and psychiatrists and they resist any questioning of their authority or their expertise in the programs.

Another relevant section of this report deals with the' call for increased evaluation of the programs as being one of the most popular recommendations of observers both inside and outside the federal bureaucracy in recent years. To quote the report, "Hypothetically its appeal (program evaluation) is irresistible. How else can citizens hold their public institutions accountable unless they know something about the efficiency and effectiveness of public programs? And how else can policy makers make rational decisions if not on hard information generated by the comprehensive system of evaluation? Without such a system, as is now often the case in government, decisions are made on the basis of guess work and in some instances, on far worse cirteria (i.e., personal prejudice and bias, cronysm, political deals, and the like)."

In a letter to the Naders Task Force, Dr. Ernest Gruenberg of Columbia University outlined the preconditions for scientifically valid and meaningful evaluation of social programs of which mental health is one. 1) the objective of the program must be stated in such a way that the objective data can indicate whether or not the decided statement of affairs is present. This means that specific goals must be stated which lend themselves to scientific measurement. 2) there must be a way of judging what would have happened with respect to the objective if the program had not been institued and executed. In addition, an evaluation must be replicated many times to produce a meaningful overall picture of the program. Replication is very important from the scientific standpoint in order to substantiate the validity of any experiment or program. 
to measure performance should only be openly and explicity negotiated among the various interested groups concerned. Once such standards have been established, the process of evaluation and oversight must, be ongoing; quality ratings for any program facility or practitioner should be public information."

The authors describe a model that attempts to objectify the evaluation of programs in quality of care. The model presented is called the goal attainment scaling model.

Finally, Gruenberg stated that the present evaluation methodologies are in a primitive state of development. Conclusions from this are that scientifically valid evaluation of community mental health programs is presently unfeasible. Moreover, notes Gruenberg, the widely accepted and dependable methodologies for measuring the effectiveness of either mental health treatment or service delivery are lacking. Thus, evaluation of the mental health field is primarily dependent upon the values held by the evaluator.

Further on, the report notes that as mental health care grows more expensive - in terms of both tax dollars and fee for service payments - and as the tools and techniques (chemical, electrical and surgical as well as phschological) available to the practitioner grown more varied and sophisticated, the need for some sort of quality of control becomes crucially important. At the very least, writes the authors, "There should be relevent licensing requirements, greater responsibility on the part of ethics committees and the development of adequate peer review." These mechanisms have failed to a noticeable degree especially in the area of peer review. It can be no longer stated that the biases of the professional and mental health field will be countered at any stage of bureaucracy, either up or downward. Rather what is needed is an increased involvement of the public or the consumer in the mental health field.

In that sense, quality control or quality of care evaluation is often not based on sound scientific or objective criteria but rather on a process that is derived from political negotiation. Moreover, the definition of quality of care often reflects the individual biases or interest of the quality of the group that makes the definition. To produce this, the authors suggest that "in order to protect the interest of consumers and to preserve the integrity of professionals, the defining of quality and the setting down of standards by which 
Cooper, Myles E., "Characteristics of Good Key Indicators," paper presented to the Western Interstate Commission for Higher Education, Bolder, Colorado, 1970.

Cooper identifies eight characteristics indicative of "good" program performance indicators: 1) measure what they intend to measure; 2) reasonably related to effects of the program or process which established to achieve designated goal; 3) minimally affected by other processes; 4) truly representative of progress toward the defined goal; 5 ) easy to define; 6) easy to county; 7 ) readily available, and 8 ) reliable.

Donabedilan, Avedis. Evaluating the Quality of Medical Care, Milbank Quarterly, 44 (June 1966): 166-230.

This article desribes evaluation methods for assessing the quality of medical care. It deals with the medical care process at the level of a physician/patient interaction.

There are four methods that the author lists as being specially useful for collecting data for measuring care: 1) clinical records; 2) direct observation by qualified colleagues; 3 ) behaviors and opinions; and 4) reputational surveys.

The author believes that in the end the final test of impact of the validity of the effectiveness of the care or the program or the outcome, is that which is observed in the health and satisfaction of the individual.

Eaton, Joseph W. Sympolic and Subsitive Evaluation Research, Administrative Science Quarterly, 6 (June 1962): $421-442$.

The author's thesis is that there are basically ambivalent attitudes toward evaluative research. This ambivalence is derived in part from: 1) money may be spent in ways that could better benefit clients rather than spending it on the evaluation research, and 2) the nature of research itself, that is that there is a basic assumption about exploring the unknown, and the scientific interest in asking questions and gathering data. However, this is countered by the fear of disturbing positons about the agency's operation. Thus, the bureaucratic impediments of loyalty to the organization, and fear of consequences of negative findings appear to account for high instance of symbolic research. 
Ellingson, Jack. "Effectiveness of Social Action: Programs in Health and Welfare," paper presented at the 66th. Ross Conference on Pediatric Research, Columbus, Ohio, October, 1967.

The paper examined 10 published evaluation studies which used control groups, and attempted to duplicate the conditions of the classical experimental design. These replicated studies were compentently done by well-qualified professionals in the field and the results were significant in that they were found to have little positive effect.

Ferman, Lewis A., "Some Perspectives on Evaluating Social Welfare Programs," Annals of American Academy of Political and Social Science, 385, (September 1969): 143-156.

The interesting comment in this article deals with the problem of evaluators and the interactions they have with the field staff or with the program that they are evaluating. The author, having done some evaluating and having surveyed evaluators, has found that one of the major problems of evaluation deals with staff interaction, that is, roles become somewhat merged and the personnel situations that develop are constraining.

Fleck, Andrew C. Jr., "Evaluation as a Logical Process" contained in the Canadian Journal of Public Health, 2 (March 1961): $185-191$.

The author argues that evaluation should be a logical process by which the results can be shown to be derived by the costs and the activities. The underlying assumption of this argument is that there has to be a chain (logically based) between the program and the results.

The author further states that evaluation cannot be made unless the program has: 1) a description of the underlying idea; 2) a statement of purpose which is universally understood; 3) a description of the materials devices, personnel and processes to be used; and 4) a practice of reporting results which are logically related to the rationale behind the program.

Freed, Harry M., "Promoting Accountability in Mental Health Services," American Journal of Orthopsychiatry, 42 (May 1972): 761-770.

Freed identifies eight aspects or constraints on accountability as it pertains to the community mental 
center: 1) political pressures; 2) budget area relationships; 3 ) moral or philosophical attitudes and benefits; 4) professional considerations; 5) responses from political groups; 6) reporting relations; 7) organizational structure; and 8 ) stands of control.

The author also deals with devices for promoting accountability: 1) citizens advisory board; and 2) structural forms such as a pyramidal structure.

Gregovich, Robert, "What Kinds of Measures to Use," a paper presented to the Western Interstate Commissioner for Higher Education. Bolder, Colorado, 1970.

According to Gregovich, program evaluation is going on continously, whether or not time and resources are formally being devoted to it. For example, people, clients, administrators, legislators, supervisors, and subordiantes are making judgements of value regarding community mental health programs. In order to lay some order on the myraid of possible outputs associate with programs, different authors have suggested various categories of measures. On the basis of what these authors suggest and on the basis of the author's experience, three types of measures were identified: Measures of Efficiency, Measures of Effectiveness, and Measures of Satisfaction.

Greisman, Eugene B., "An Approach to Evaluating Comprehensive Social Projects," Educational Technology, 9 (September 1969): 16-19

The author's thesis is that techniques used in evaluation will be dependent on the function which it is expected to fulfill. The primary function is usually the answering of pertinent questions about adequacy, efficiency, impact and success of the program. Other important functions may be legitimization of program, desire for feedback information for the use in decision-making, or the discovering of basic information which may be applied to other related areas.

The author also lists seven steps in evaluation and research: 1) problem identification; 2) development of an evaluation model; 3 ) operational definition of goals; 4) devising appropriate research techniques; 5) collecting the data; 6) analyzing the data; and 7) reporting the findings. 
Gross, Gertrude; Gross, Martin, Guy, William, "Evaluation of Community Base Mental Health Programs: Long range effects," Journal of Medical Care, 7 (July 1969): 23-42

In this study, the evaluation of community mental health programs was facilitated by random selection and allocations to two different treatment groups as well as to two control groups. The assessment was essentially peer review, however, the professionals who were selected to do the assessment were not those that were involved in the treatment program.

The outcomes of each of the various treatment modalities were evaluated on the basis of subjective criteria rather than on the basis of some objective standards and measures. Specifically, these subjective measures were the diagnosis of the individuals responses to the various treatment modalities. This diagnosis included such criteria as emotional withdrawal or lack of degree of suspicious, unusual thought content and hostility. Essentially, the authors used various statistical techniques to evaluate the program.

Hawkridge, David G., "Designs for Evaluative Studies," In Evaluative Research: Strategies and methods, pp. 22-47. Edited by American Institute for Research. Pittsburgh: American Institute for Research, 1970.

The author lists seven phases of the evaluation which include: 1) setting objectives for evaluation; 2) selecting objectives to be measured; 3) choosing instruments and procedures; 4) selecting samples and control groups; 5) establishing schedules for evaluation; 6) choosing analysis techniques; and 7) drawing conclusions and making recommendations.

Herzog, Elizabeth, Some Guidelines for Evaluative Research. Washington D.C.: United States Department of Health Education and Welfare, 1969.

The author lists nine areas of evaluative research: 1) the purpose of the evaluation; 2) the kind of changes desired; 3) the means by which the changes are to be brought about (to include theory and practice); 4) the trustworthiness of the categories and measures (assessment of reliability and validity should be used at this point); 5) the points at which changes are to be measured (to include baseline measurement); 6) location for sample, choice of interviewers, and the like; 7) the representativeness of the individuals or programs studies; 8) the evidence that the change observed was due to the means employed (to include adherence to the canons of scientific inquiry); and 9) the meaning of the changes found, and any unexplained consequences. 
Lemcau, Paul V., Pasamaick, Benjamin, "Problems in Evaluation of Mental Health Programs," American Journal of Orthopsyehiatry, 27 (January 1957): 55-58

The authors contend that most mental health programs are too complex and comprehensive to be evaluated under present guidelines (1957). The use of genuine control groups and behavioral rather than opinion indicators should improve evaluation, however, the vague nature of many mental health programs does not allow for measurable goals and much less measurable results.

Mann, John, The Outcome of Evaluative Research in Changing Human Behavior, New York: Charles Scribner's \& Sons, 1965 .

The author argues that mental health, psychotherapy, counseling programs, etc., are too complex to evaluate under operating conditions. The author states that in place of program evaluation, laboratory research for the study of behavior change strategies should be explained. Only with tight controls, isolation of specific program components, and factor analysis can generalizations be made.

McIntyre, Margureite H., et al., "Components of Program Evaluation Capability in Community Mental Health Centers," in Resource Materials for Community Mental Health Program Evaluation, pp. 4-50. Edited by Wm., A. Hargreaves, et al., San Francisco: Langley Porter Institute, 1974 .

The authors thesis is that although program evaluation is a useful and relevant tool to program management, planning and development is not yet a functional reality. This reluctance to commit resources to the development of evaluation capability stems from the uncertainty that investment in evaluation will not result in viable solution to the complex political and social problems facing community mental health centers. However, with the growth of programs, the multiplicity of demands for accountability, the completion for resources, the reduction in categorical funding for mental health programming, and the growth of third party funding, evaluation capability is becoming necessary for future community mental health programs survival and effectiveness.

Further on, the author's assert that successful evaluation in the community mental health clinics requires the integration of political and social dimensions into its spheres of analysis, as well as considering the subjective realities of organizational participants. 
The author's also posit a working model for mental health evaluations. The model described identifies components of an evaluative process that aim to enhance effective management decision-making and improve clinical performance. The three dimensions of the evaluative matrix are: 1) LEVELS OF EVALUATIVE ACTIVITIES, which include: basic systems resource management, client utilization, outcome intervention and community impact monitoring; 2) FUNCTIONAL ROLES OF THE EVALUATOR, which include clerical-statistical, clinical research, technical/ evaluative, and coordinative decision-making roles; and 3 ) INFORMATION CAPABILITY, which evolves along a continuum ranging from unplanned and uncoordinated natural data banks to planned access data systems supported by allocated resources.

National Institute of Mental Health (Ed.), Planning for Creative Change in Mental Health Services: Use of Program Evaluation
of Mental Health, 1972 .

This publication contains three units on the uses of program evaluation in mental health services. The first unit covers the use of program evaluation in front line services. In the second unit a bibliography on evaluation research is provided. The third unit presents abstracts of works on evaluative research. The following review is confined to the first unit.

The first unit states that program evaluation is used by the National Institute of Mental Health as a means of instituting program change in services improvement through planning. Essentially evaluation will fulfill three functions: 1) it will identify problems and needs that indicate change; 2) it would be utilized for research to provide solutions for effective change in programs to meet needs; and 3 ) it would be used as a strategy for gaining concensus for the adaption of change in the system.

This first unit is also concerned with the use of program evaluation and front line services. Identification of eleven principles underlying the soundness of evaluation were identified: 1) utilization of advisory group; 2) evaluation should be continual; 3 ) consideration of impact on total system rather than on goal achievement; 4) parsimony is essential; 5) evaluation should be conducted within the context of clear objective goal statements; 6) the evaluation should consider not only the attainment of the goal but what actions account for the attainment; 7) planning effort should be devoted to the consequence of any evaluation prior to the beginning of the evaluation; 8) utilization of unobtrusive measures 
whenever possible; 9) testing of measuring instruments; 10) use of classical experimental designs whenever possible; and 11) results of evaluation should be distributed through the community.

The authors also present two models for approaching program evaluation: 1) key factor analysis; and 2) goal attainment scaling.

Smith, J.J., "Twelve Steps to Effective Program Evaluation," paper present to the Western Interstate Commissioner for Higher Education, Bolder, Colorado, 1970.

In this paper, the author identifies twelve steps to effective program evaluation, dividing them into program planning steps and evaluative steps. The program planning steps describe the conditions which must be met before evaluative program analysis can occur. PROGRAM PLANNING STEPS: 1) program definition; 2) assessment of need; 3) goal specification; 4) documentation of program activities and 5) relevance of program activity. EVALUATIVE STPES: 1) development of indicators; 2) data specification; 3) data collection; 4) data analysis; 5) reporting information; 6) program modification; and 7) periodic reassessment.

Suchman, Edward A., "Action for What?: A Critique of Evaluation Research," In Organization, Management and Statistics of Social Research, Edited by Richard O'Toole. Cambridge: Shenkman Publishing Co., 1970.

The author points out that evaluation makes three assumptions: 1) man can change his social environment; 2) change is good; and 3 ) change is measureable. Further on, the author identifies various factors which are essential for successful evaluation. These factors include: 1) objective program and criteria for measuring change are essential; 2) evaluation must be related to the decisionmaking process; 3 ) evaluation should be timed right; 4) it should come after the program has become operational, but before the effect has become observable; 5) it should continue over a period of time after the program has ended, if in fact it ends, or past the operational end of it, such that the effect of the program on the situation can be observed; and 6) once a program is in operation, the evaluation must focus on the improvement of services. This latter type of evaluation requires a model which stresses the feedback of the continous stream of information into the ongoing process. The basic design of evaluative research, whether of the before, after or during variety, must include a description and analysis on input, an understanding of the 
cause and process which leads to change, and a definition of the objective in terms which permit the measurement of attainment, Three common designs are the case study, the survey and experimental and control groups after a program, and the perspective study done periodically on experimental and control groups.

Wittington, H.G, and Stenbarger, C,, "Preliminary Evaluation of the Decentralized Community Mental Health Clinic," American Journal of Public Health 60, (September 1970): 64-77.

The evaluation tools used by the authors in this study were surveys of opinions on decentralization by the patients, the care givers, administrators, and staff. In the patient opinions, samples of patients released by the mental health center prior to decentralization were compared to the results of opinion surveys to a similar group of matched patients relased by the center after undergoing treatment under the decentralized framework. The results indicated that the decentralized approach was beneficial (all respondents indicated treatment helped considerably and that the worker wanted to help, but also responded in terms of 'secretary was nice', how fast patient was seen, and how well problem was understood.) Similar results were seen in surveys from other areas.

For example, staff, administrators and care givers, felt that decentralization was a valuable concept. The authors felt that decentralization would advance the goals of availability, comprehensiveness, continuity and economy of care.

In addition to surveys, the authors reviewed selected indices of program efficiency. These program efficiency indices included: Treatment activity intake indices, efficiency in program ratios and patient staff hour ratios, staff utilization, cost of service unit after care, consultation indices and percentage of staff. 
APPENDIX A:

AGENCY QUESTIONNAIRE 
BACSGROUND INIORHATION

1. Name of Agency

2. Director of Agency

3. A. Is there a bcard of directors or advisory board? Yes No.

(Please indicate which one) If yes, how many persons serve?

What are length of tenns of service? How frequently do they meet? Average attendance

Are there any proscriptions as to board membership; i.e. certain number from target groups, ect. Yes No - If yes, please describe

What are the functional committees of the board?

Responsibilities

How frequently do board and "line" staff meet?

$-$

B. If you do not have a board of directors, who sets major policy for the agency operation?

4. Who is responsible for:

Agency goal setting

Agreements with other agencies

Internal Cormunications

Financial \& records management 
4. (Cont.)

Coordination with other Cormunity Agencies

Staff selection

Staff promotion

Staff release

Addition of programs

Deletions of programs

Program evaluation

5. A. Describe each program goals and objectives provided along with staff (with qualifications), assigned staff/patient ratio, budget allocation; \& no. of persons seen during the last 12 months. i.e.:

Family Counseling (description)

i.e. e.

Staff: one M.A. Clin $450 \%$ of Time

- $\quad$ One MSW 10\% of Time

One PHD. $10 \%$ of Time

Budget: $\$ 45,000$

Clients : 500 families

Use additional sheets if necessary.

Page 2 HWPC:po

10-14-74 
5. B. Do you anticipate any new programs in the near future? Yes No. If yes, please describe.

6. A. Please identify each staff position, qualifications, and proportion of time available for treatment.

Staff Position

Qualifications

\% of Treatment Time

B. Do you utilize outside Consultants \& Specialists? Yes No If yes, what kind and how frequently?

$\div$

C. Please indicate your organizational chart. 
c. (Cont.)

7. How many permanent stafi persons have resigned in the past year?

8. Do you have any difficulty getting and keeping qualified staff? Yes No If yes, please describe

9. Do you utilize paraprofessionals? Yes. No - If yes, please describe their function.

10. Do you utilize volunteers? Yes No - If yes, please describe their function and utilization.

11. Describe your in-service training program, i.e.; frequency, duration, outside consultants, type of training, etc. 
12. Are any of your staff taking outside revelant training? Yes No If yes, please describe

13. Describe the physical facilities for your program,

14. Are there any evident problems either in the facility itself or in its location?

15. Please indicate the major sorrces of operating revenue:

Type $\%$

Private Fees

Private Insurance

State Grant-in-aid

Clark County (fees or millage)

Federal Title XIX

Federal (VA)

Grants/Contracted (Indicate type \& source)

UGV

Other (Indicate)

16. Do you have any restrictions on the services you provide or clients you serve imposed by your funding sources. Yes No Please explain 
17. Do, you have any grants or contracts pending? Yes No If yes, please indicate amount and type.

18. How much administrative and/or professional time is being spent in obtaining funding?

Is this higher or lower than you would like?

19. Have you identified costs per client by type of "presenting problem" diagnosis service provided, etc? Yes No Please describe

20. A. Please describe any program evaluation done by your agency personnel.

B. How much staff time does this require?

21. A. Please describe any client evaluation done by your agency personnel.

B. How much staff time does this require?

HTPC/PO

$10 / 14 / 74$

Page 6 
22. Please describe any "outside" evaluations done in the past 5 years. May we have a copy of the results?

23. A. Please describe any basic research being done by your staff.

B. How much staff time does this require?

24. Do you measure recidinism or relapse of your patients? Yes No

Please provide, if available, the percentage of relapse by program area.

i.e.: (identify program)

$\%$ relapse

Drug Program

Alcohol Program

25. A. Please describe any procedures for follow-up of patients when they are referred to other programs within your agency.

B. Describe the procedures for follow-up of referrals to other agencies or professionals. 
25. Cont.

C. What information do you send to other professions and agency's on former clients.

26. What procedures do you have to assure continuity of care between your agency and other community agencies?

27. From which agencies will you accept their diagnostic evaluations of the client?

28. Describe the normal intake process, indicating evaluation procedures, time delays, and assignment of patient to staff.

29. How do you determine staff load?

HIVPC $/ \mathrm{pO}$

$-10 / 14 / 74$

Page 8 
29 Cont.

If a staff person has no more treatment time, what happens to the patients waiting for his program or time?

30. Do you have a waiting list for services? Why or thy not?

31. What consultation or educational services have been provided by your agency to cormunity sources last year?

Type of Consultation/Education

Beneficiary

Approx. \#

of Hours

Page 9

HUPC: po

$10-14-74$ 
32. With which of the following agencies or individuals has your program had contact during the past month and what was the nature of your contact? Also estimate number of hours during month with each agency or individual.

1. local health department

2. physicians

3. psychiatrists in private practice

4. Recovery, Inc.

5. Private Social Agencies

6. nursing homes

7. D.S.H.S.

8. the courts

9. Law Enforcement

10. schools

11. the clergy

12. recreation departments

13. OFO Programs

14. Veteran's Hospital

15. Conmunity Hospitals

16. Columbia View

- 17. Information \& Referral

18. Other (Indicate)

33. Do you have any systematic method of assessing target groups that might need service? Please describe and identify those that you have identified. 
34. If so', do you have any programs to disseminate information specifically to those target groups regarding:

factors which produce mental stress

early signs of mental and behavioral dysfunction

resources for help with mental/behavioral problems

35. Do you conduct any programs for the general public designed to increase understanding of :

factors which produce mental stress

early signs of mental and behavioral dysfunction

resources for help with mental/behavioral problems

36. Do you have any outreach programs to meet the needs of target groups identified by your agency? Please describe

Please describe the formal and informal relationships established between your agency and the state mental institutions.

Page 11

HWPC: $p 0$

10-14-74 
Describe any programs that you classify as "prevention".

What types of prevention programs would you like to be involved in if you had the funds?

Page 12

HWPC:Po

10-14-74 
Please provide:

Any evaluation Studys

By-laws

Personnel Policies

Copies of Coordinating Agreements

Page 13

HWPC: $P O$

10-14-74 
APPENDIX B:

DETECTOR AND PROVIDER QUESTIONNAIRE 


\section{SCHOOL COUNSELORS/PRINCIPALS}

We are trying to get a comprehensive view of the mental health problems in Clark County. In order to get an idea of the extent of the problems by age group, we are seeking the help of professionals in our community, including yourself, physicians, clergymen, and other principals or school counselors. We would like very much to have your cooperation in completing the enclosed information, insofar as - possible. Please return this form no later than October 15, 1974.

1. School name 2. School population

2. Do you have classes for emotionally handicapped?

3. How many are being served?

4. How are students selected of placement in the Emotionally Handicapped classes?

5. In an average year, how many youngsters do you feel are in nead of services for mental or emotional problems? (include those identified in \#3).
$\mathbf{K}-3$
$4-6$
$7-9$
$10-12$

6. How many youngsters identified in 5 (above) are referred to any of the following:

Served by Special Services Children's Home Society

Mental Health \& Family Services Catholic Family Services

Private Physicians Juvenile Court

Private Psychologists Southwest Wash. Alcohol Recovery Foundation

Private Psychiatrists

Other (please list)

Kalser

Health Department

Department of Social and Health services

7. Each year, approximately how many youngsters can you identify within the following catagories:

Drug abuse problems Abused/neglected child 
Alcohol abuse problems

Serious mental (emotional) disorder

Upset due to family crises

Less serlous social adjustment problem

Hyperactive (minimal brain dysfunction)

8. What is the most prevalent reason why in some cases you or your staff do not make referrals to community agercies (Please indicate major reason, $\# 1$, next $\# 2$, and $\# 3$ ).

It is suspected that the parent will not follow up

Long waiting lists at some agencies

Unfamiliar with some agency's programs

"Special services" handles all cases

Poor results from previous referrals

Cost is excessive

Other (indicate)

9. What percentage of parents follow-up on referrals by you or your staff?

10. What are the major reasons for parsn:

Lack motivation

Lack money

Lack transportation

Don't see the need

11. In your opinion, do you. feel the need for more mental health consultation?

- How many hours a month would be helpful?

12. What additional services do you feel are most vitally needed now? (Rank $\# 1, \# 2, \# 3)$.

1. Family Counseling

2. 24 hour crises counseling

3. Drug abuse

4. Alcohol Abuse counseling

5. Parent training

6. Consultation to schoof personnel

7. Psychiatric Hospital

$-2-$


8. Individual Counseling

9. Group Therapy

10. Other (list).

13. Have you made any curriculum or administrative changes in your school in the past several years for the express purpose of preventing mental problems or promoting mental well being?

Please describe

14. Please rank the service provided, as you have observed it, for the following agencies providing counseling or mental health services:

outstanding Good Fair. Poor

Special Services

Mental Health \& Family Service

Catholic Fainiry Services

Children's Home Society

Baiser

Private Physicians

Private Psychiatrists

Dept. of Social \& Health Services

Juvenile Court

Health Department

Private Counselors

15. Do you have any other comments or suggestions to help us in our study?

16. Do you wish to have a copy of the results? 
We are trying to get a comprehensive view of the mental health problems in clark County. We are seeking the help of several professions, including clergymen, in our community, in providing us information about the people they serve. Will you take a few minutes, today, and complete the following information. Thank you.

1. Number of members in congregation

2. Average congregation attendance on a Sunday

3. How many persons have cane to you for help with emotional or mental problems in the past year

4. Please indicate the number of persons seen in the following catagories in the past year:

\begin{tabular}{rrrrrr}
\hline & & & \multicolumn{2}{c}{ Age Ranges } & \\
& & $0-17$ & $18-50$ & $50-64$ & $65+$ \\
\hline
\end{tabular}

Serious mental (emotional) problems

Life adjustment problems

Family crises

Alcohol problems

Drug problems

Lentally retarded

5. What general disposition do you make with the above cases (approximate number)

a. Handle it yourself

b. Refer to physician

c. Refer to psychiatrist

d. Refer to private psychologist/counselor

e. Mental Health \& Family Services Center

1. Health Department

g. Veterans Hospital

h. Columbia View 
1. Soutbwest Washington Alcohol Recovery Foundation

j. St. Joseph's Alcoholism treatment program

k. School "Special Services" unit

1. UGN Agency

m. Fantly Court

6. What is the most prevalent reason why, in some cases, you do NOT make a referral to community agencies (please indicate major $\sharp 1, \# 2, \# 3$ )

It is suspected that the patient will not follow-up

Iong waiting lists at some agencies

Poor resultis from previous referrals

Unfamiliar with scue agency's programs

Cost is excessive

$\therefore$ Patients prefer private psychiatrists/psychologists rather than public agency

Image of commity agency is that oi one "serving poor"

Other (indicate)

Agency personnel tend to be "anti-religious"

7. How many hours per month do you spend in counseling?

Would you utilize consultation if it were available?

If yes, how frequently.

8. What additional services do you feel are most vitally needed now? (Rank $\pi 1, \# 2, ~ \# 3$ )

1. Family counseling

2. 24 Hour crises counseling

3. Drug abuse

4. Alcohol Abuse counseling

5. Parent training

6. Consultation to school personnel

7. Psychiatric Hospital

8. Individual Counseling 
9. Group Therapy

10. Other (list)

13. Have you made any curriculum or administrative changes in your school in the past several years for the express purpose of preventing mental problems or pramoting mental well being?

Please describe

14. Please rank the service provided, as you have observed it, for the following agencies providing counseling or mental heal'th services:

Outstanding Good Fair

Poor

Special Services

Hental Health \& Family Service

Catholic Family Services

Children's Home Society

Raiser

Private Physicians

Private Psychiatrists

Dept. of Social \& Health Services

Juvenile Court

Health Department

Private Counselors

15. Do you have any other corments or suggestions to help us in our study?

il cuis wor sidecuped? 
Physicians

We are trying to get a comprehensive picture of the mental health problems in clark County. We are seeking the help of the physiclans because it is suspected that you will have the best information as to the need for mental health services. We will appreciate your answering the following questions and returning this as soon as possible.

1. Field of Practice

2. Approximate number of patients seen monthly

3. Approximation of number of patients in a month in each of the following categories :

\section{Category}

0-17 18-50

$50-64$

$65+$

a. psycknmanzetic

b. psychotic

c. disturbed with physiological bases

d. mentally retarded

e. family crises

(1.e., marital problems)

f. alcohol problems

g. drug problems

h. personality disorders

1. hyperactive children

1. other adjustment problems

k. physical problem with potential emotional bases

(1.e., migraine, ulcer, asthma)

1. abused/neglected chlld 
4: What general despositlon do you make with the above cases? (Approximate number)

a. bandle it yourself

b. refer to another physician

c: refer to psychiatrist

d. refer to private psychologist/counselor

e. Mental Health \& Family Services Center

f. Health Department

8. Veteran's hospital

b. Columbir Vlew

1. Southwest Washington Alcoholism Recovery Foundation

J. St. Joseph's Alcoholism Treatment Program

k. School "Special Services" unit

1. O.G.N. Agency

m. Family Court

5. What is the most prevalent reason why, in some cascs, you do not make a

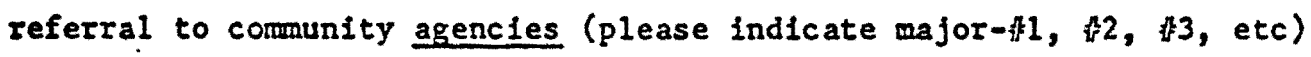

It is suspected that the patient will not follow up

Long waiting lists at some agencles

Poor results from previous referrals

Onfamiliar with some agencys' programs

Cost too excessive

Patient prefers private psychiatrists/psychologists rather than public egency

Image of community agency is that of one "serving poor"

Other (Indicate) 
6. In your opinion, do you see the need for more mental health consultation?

If yes, how many hours a month would you deem desirable?

7. What additional services do you feel are most vitally needed now? (Rank $11, i 2, \$ 3$, etc.)

- family counseling

b. 24 hour crises counseling

c. drug abuse

d. alcohol abuse

e. parent training

f. consultation to school personnel

8. physhiatric hospital

h. Individual counseling

1. group therapy.

f. other (1ist)

8. Have you made any curriculum or administrative changes in your school in the past several years for the express purpose of preventing mental problems or promoting mental well being?

(please describe)

9. Please rank the service provided, as you have observed it, for the following agencles providing counseling or mental health services:

\section{Outstanding Good Fair $\underline{\underline{P} \text { Por }}$}

Speclal Services

Mental Health \& Family

Services

Catholic Family Services 
9 continued

Outstanding Good Fair $\underline{\underline{P} \text { oor }}$

Children's Home Soclety.

Raiser

Private psyciniatrists/physicians

Department of Social and

Health Services

Juvenlle Court

Health Department.

Private counselors 
Private Counselors/Psychiatrists/Psychologists

1. What types of problens do you specialize in?

2. What general methodology do you follow? (\% of treatment time)

a. individual treatment

i. Group treatmi=t

c. Group awareness

3. Approximate number of patients seen monthly

4. Approximation of number of patients in a year seen in the following categories: Category

0-17 $18-50$

a. psychoneurotic

b. psychotic

c. disturbed with psychologist bases

d. mentally retarded

e. family crisis

(1.e., marital problens) 
4 continued

Category

E. alcohol problems

8. drug problems

h. personality disorders

1. hyperactive children

1. other adjustment problems

k. physical problem with

potential emotional bases

(i.e., migraine, ulcer, as thma)

1. abused/neglected child

5. Please indicate the number of persons each year referred to you from the following sources:

a. private physicians

b. private psychologists/

counselors

c. Hental Health \& Family Services

d. Children's Home Society

e. Family Court

f. Department of Social \& Health Services

E. Schools

h. Hospitals

1. Other

6. What additional services do you feel are most vitally needed now? (Rank $41,42,43$ )

a. family counseling

b. 24 hour crises counseling.

c. drug abuse

d. alcohol abuse 
6 continued :

.e. parent training

f. consultation to school personnel

8. psychiatric hospital

h. Individual counseling

1. group therapy

3. other (11st)

7. Have you made any. curriculum or administrative changes in your school in the past several years for the express purpose of preventing mental problems or prowoting mentil well being?

Please describe

8. Please rank the service provided, as you have abserved it, for the following agencies providing counseling or mental health services:

Outstanding Good Fair Poor

Special Services

Mental Health \& Fanily

Services

Catholic Family Services

Chlldren's Home Society

Raiser

Private physicians/

psychiatrists

Department of Social

\& Health Services

Juvenile Court

Health Department

Private Counselors 
APPENDIX C:

CONSUMER QUESTIONNAIRE 
1. Please circle the numbers that describe how you felt when you ilist sought help at the Mental Health and Fanily Services Center:

\begin{tabular}{lccccc} 
& $\begin{array}{c}\text { Strongly } \\
\text { Disagree }\end{array}$ & Disagree & Undecided & Agree & $\begin{array}{c}\text { Strongly } \\
\text { Agree }\end{array}$ \\
Inadequate & 1 & 2 & 3 & 4 & 5 \\
Bad & 1 & 2 & 3 & 4 & 5 \\
Upset & 1 & 2 & 3 & 4 & 5 \\
Fearful & 1 & 2 & 3 & 4 & 5 \\
Calm & 1 & 2 & 3 & 4 & 5 \\
Confident & 1 & 2 & 3 & 4 & 5 \\
Other (please describe) & & & & 5 \\
\hline
\end{tabular}

2. As you reflect on how you feel, now, will you indicate whether you disagree or agree:

\begin{tabular}{lccccc} 
& $\begin{array}{c}\text { Strongly } \\
\text { Disagree }\end{array}$ & Disagree & Undecided & Agree & $\begin{array}{c}\text { Strongly } \\
\text { Agree }\end{array}$ \\
Inadequate & 1 & 2 & 3 & 4 & 5 \\
Bad & 1 & 2 & 3 & 4 & 5 \\
Upset & 1 & 2 & 3 & 4 & 5 \\
Fearful & 1 & 2 & 3 & 4 & 5 \\
Calm & 1 & 2 & 3 & 4 & 5 \\
Confident & 1 & 2 & 3 & 4 & 5 \\
Other (please describe) & & & & \\
\hline
\end{tabular}


3a. Do you still have the same problem(s) that you came to the Mental Health and Family Services Center with? Yes No Are you able to handle these problem(s) differently now? Yes No

3b. When you first came to the Mental Health and Family Service Center, what did you expect to get out of coming?.

3c. How would you rate your reaching the above expectation, Now? (check which one applies)

Completely met my expectation
Met it quite a bit
Don't know
Met my expectation very little
Did not meet it at all


4. The following describe how some people feel about the services of the Mental Health Center and Family Services Center. Will you rate how you feel about each of the items?

Friendly staff

Appropriate dress \& Appearance

Capable staff

Comfortable setting

Flexible hours

Staff "on Time"

Reasonable fees

Easy to talk to

Choice of treatment

Help you with problems

Good Iocation

Not too far from home

Short waiting time

Highly skilled staff

\section{DISAGREE}

$$
0
$$

0

0

0

0

0

0

0 .

0

0

0

0

0

0
1

.

$$
?
$$$$
1
$$

1

1

1

1

1

I

1

1

1

1

2

2

2

2

2

2

2

2

2

2

2

2

2

2

$\begin{array}{ll}3 & 4 \\ 3 & 4\end{array}$

3

$\begin{array}{llll}3 & 4 & 5 & 6\end{array}$

34

34

56

AGREE

3456

3456

34

56

34

56

34

56

34

56

34

56

3

3

3

56

$4 \quad 5.6$

other

5. Considering your experiences at the Mental Health and Family Services Center, would you recomend the Center to your friends? Have you recommended it to anyone within the last year? Who? (friend, relative, etc.) 
6. Had you seen any other agency or professional helping person prior to your first visit to the Mental Health and Family Services Center? Would you tell us who or what agency it was?

7. Have you seen any other agency or professional helping persons about your problems since you first visited the Mental Health and Family Services Center? If yes, would you mind telling us who or what agency it is?

8. Did you feel free to discuss your problems with the therapist you saw at the Mental Health and Family Services Center?

9: How did the Mental Health and Family Services Center help you? (check more than one if appropriate)

\begin{tabular}{|l|l|}
\hline Helped to understand my problems & \\
\hline Helped to understand myself & \\
\hline Helped to understand my friends/relatives & \\
\hline Other (please describe) & \\
\hline Did not help me & \\
\hline
\end{tabular}


10. Will you indicate whether you know about or have used the services of the agencies listed below?

\begin{tabular}{|c|c|c|c|}
\hline \multirow[b]{2}{*}{ Catholic Family Services } & $\begin{array}{l}\text { Krow About } \\
\text { Yes or No }\end{array}$ & $\begin{array}{l}\text { If yes, what } \\
\text { service do you } \\
\text { jenow about? }\end{array}$ & $\begin{array}{l}\text { Have you } \\
\text { ever used } \\
\text { this service? }\end{array}$ \\
\hline & & & \\
\hline Familv Court & & 1 & \\
\hline Juvenile Probation rept. & & $i$ & \\
\hline $\begin{array}{l}\text { Vancolver Special Services } \\
\text { Dept. }\end{array}$ & & & \\
\hline $\begin{array}{l}\text { Evergreen Special Services } \\
\text { Dept. }\end{array}$ & & & \\
\hline $\begin{array}{l}\text { Dept. of Social and Health } \\
\text { Services: Housekeeping services }\end{array}$ & & & \\
\hline Day Care Services & 1 & & \\
\hline Welfare & & & \\
\hline Counseling & 1 & & \\
\hline Medical Coupons & & & \\
\hline Vocational Rehabilitation & 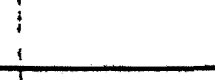 & 1 & \\
\hline $\begin{array}{l}\text { Southwest Wash. Alcohol Recovery } \\
\text { Foundation (SWARF) }\end{array}$ & 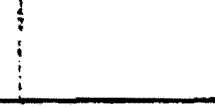 & $\vdots$ & \\
\hline $\begin{array}{l}\text { St. Joseph's Alcohol Treatment } \\
\text { facility }\end{array}$ & 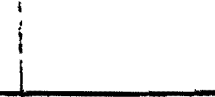 & 1 & \\
\hline Any Portland agency & & & \\
\hline Private Counselors or professionals & & & \\
\hline Acoholism Detoxification Center & & $i$ & \\
\hline Children's Home & & 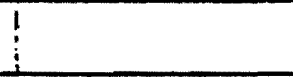 & \\
\hline
\end{tabular}


21. Do you have any other suggestions or coments that would help the Mental Health and Family Services Center in planning for the agency program?

12. If you are not now going to the Center, will you tell us why not.

That is all of our questionnaire, except for. a few questions about you. Age Sex

Marital Status: Never married Married Remarried

Divorced Separated Widowed

What was the highest grade completed in school?

Did you take any rocational courses? How many years?

What do you consider to be your primary occupation?

How many times have you visited the Mental Health Center (include this visit)

When was the last date, approximately, that you visited the Mental Health and Family Services Center.

$\overline{\text { Month } / \text { Year }}$

